Universidad de Lima

Facultad de Comunicación

Carrera de Comunicación

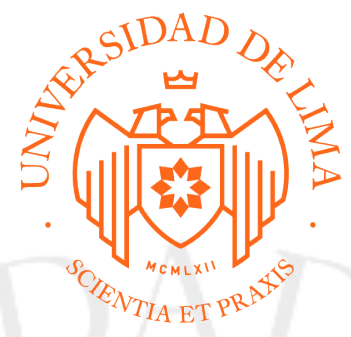

MUJERES Y ARENA:

PORTAL INFORMATIVO SOBRE

VIOLENCIA BASADA EN GÉNERO EN

VILLA EL SALVADOR

Trabajo de Suficiencia Profesional para optar el Título Profesional de Licenciado en Comunicación

Daniella Toce Salcedo

Código 20111252

Lima - Perú

13 de mayo 2019 


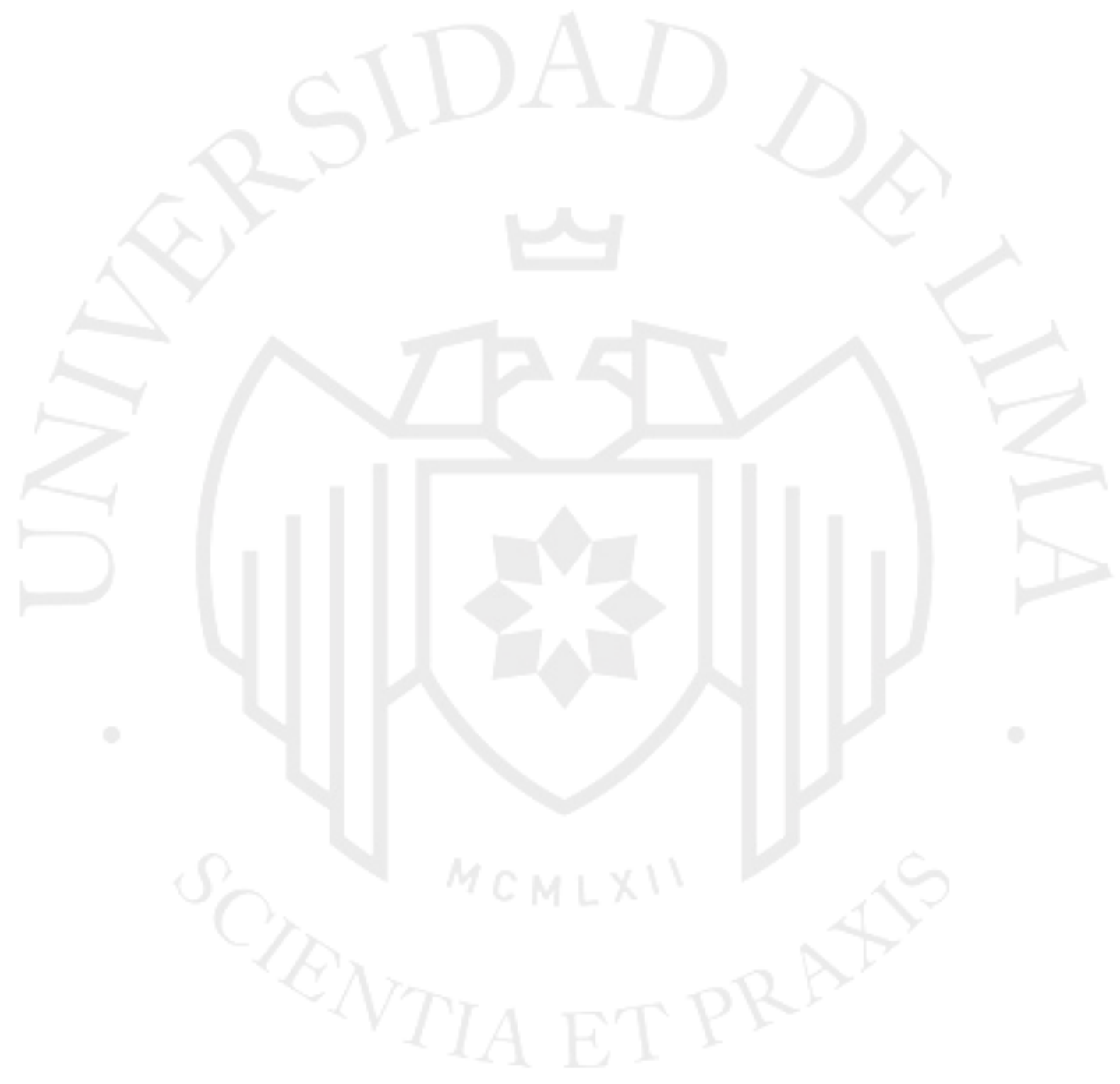




\section{MUJERES Y ARENA: PORTAL INFORMATIVO SOBRE VIOLENCIA BASADA EN GÉNERO EN VILLA EL SALVADOR}




\section{ÍNDICE}

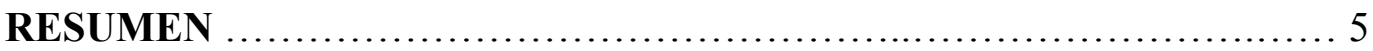

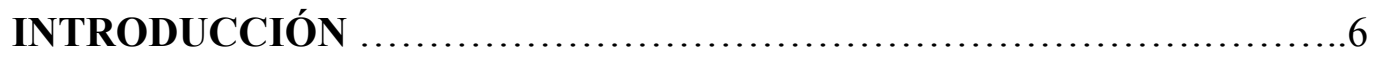

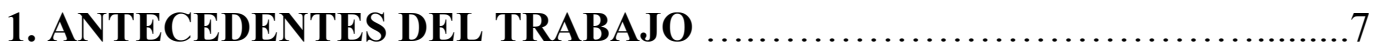

1.1 La violencia de género como conflicto social ......................7

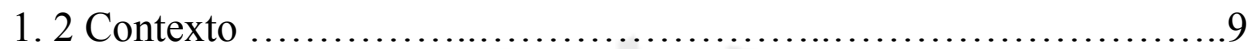

1.2.1 Realidad de la violencia de género en Perú actual ..................9

1.2.2 Villa El Salvador.............................................12

1.3 Diagnóstico de antecedentes ...................................13

1.3.1 Las representaciones de la mujer en productos mediáticos..........14

1.3.1 Informar sobre la violencia.................................... 19

1.3.2 Micaela De Osma...............................................21

1.3.3 Cindy Arlette Contreras ....................................26

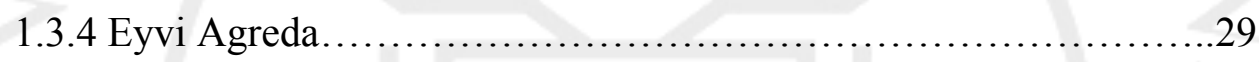

2. PROPUESTA DE COMUNICACIÓN .....................................

2.1 Estrategia............................................... 34

2.1.1 Periodo de la estrategia........................................34

2.1.2 Objetivo general .............................................34

2.1.3 Objetivos específicos .......................................34

2.1.4 Mensaje principal.........................................34

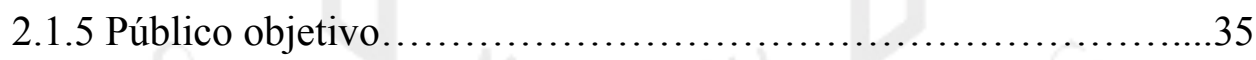

2.1.6 Canales de difusión........................................... 35

2.1.7 Financiamiento............................................

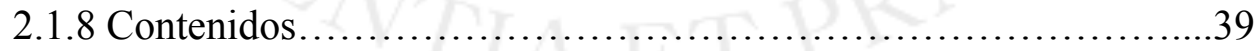

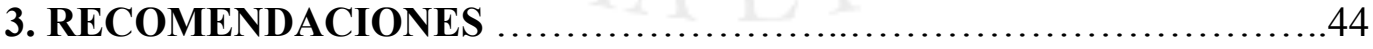

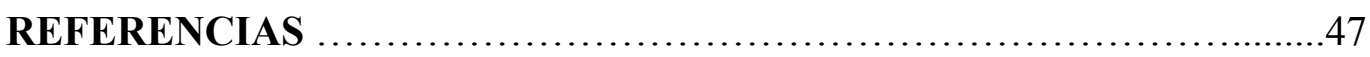

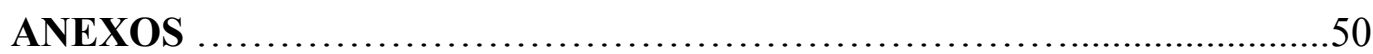




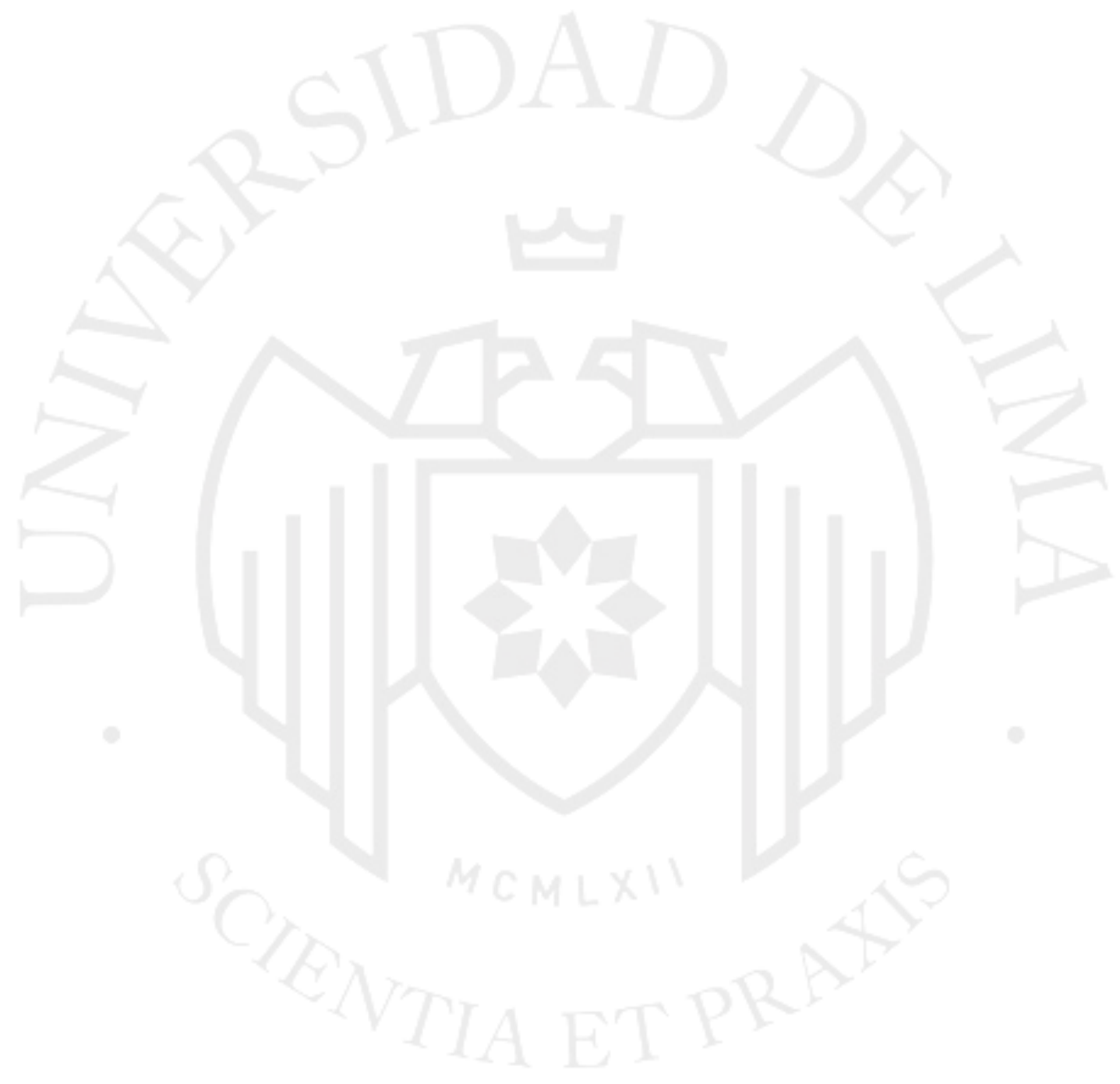




\section{RESUMEN}

Mujeres y Arena es una historia que cuenta la realidad de la violencia basada en género en el distrito de Villa El Salvador. Desde la presentación, la situación de violencia en el Perú y en el distrito y las consecuencias que esta tiene sobre sus habitantes y el desarrollo de los mismos. Presenta datos estadísticos sobre números de violencia y el impacto económico de la misma sobre la sociedad, para tener una idea de las consecuencias en un concepto tangible como es el valor monetario. Finalmente, presenta las historias de mujeres de Villa El Salvador que, desde distintos frentes, vienen trabajando por la eliminación de la violencia basada en género y el empoderamiento de las mujeres. 


\section{INTRODUCCIÓN}

Mujeres y Arena cuenta la historia de las mujeres de Villa El Salvador. Mujeres de lucha, que a través del esfuerzo y comunidad han logrado construir grandes cosas a lo largo de los años. La ciudad en el arenal, la cooperación entre colectivos, la comunidad entre personas desconocidas y una red de apoyo para quienes necesiten. Frente a la dura realidad de la violencia basada en género en el país, las mujeres de Villa El Salvador, un distrito muy violento, han empezado a construir, desde diferentes frentes, iniciativas que empoderen a sus compañeras, que las puedan ayudar a salir de sus situaciones de vulnerabilidad. Ya sea a través de la expresión artística, el aporte a la política local o transmitiendo el conocimiento que Villa les ha dado, estas mujeres están poniendo un grano de arena más para poder acabar con la violencia en sus vidas y las de las demás. Para que puedan construir una vida justa, con posibilidades de desarrollarse plenamente. 


\section{ANTECEDENTES DEL TRABAJO}

\subsection{La violencia de género como conflicto social}

"Cuando hablamos de conflicto, no nos referimos solo a los conflictos armados, ya que existen otras clases de conflictos que aunque no utilizan armas, pueden llevar aparejada violencia y pueden tener efectos negativos sobre la población.

La palabra conflicto implica una falta de acuerdo entre dos o más personas, pero cuando esa falta de acuerdo persiste en el tiempo y afecta a un grupo grande de individuos o hace que varios grupos sociales se enfrenten, podemos hablar de conflicto social." (ACNUR, 2018)

Como una de tres principales causas de conflicto social, el Alto Comisionado de las Naciones Unidas para los Refugiados (ACNUR) reconoce la desigualdad entre hombres y mujeres, personas de distintas etnias o que profesan distintas religiones; además la crisis económica que puede llevar al desempleo y proliferación de empleo informal y peligroso, y la ausencia del Estado en ciertos espacios de la comunidad, que puede llevar a acrecentar las brechas de desigualdad y generar conflicto.

Lewis Coser define el conflicto social como "una lucha con respecto a valores y derechos sobre estados, poderes y recursos escasos, lucha en la cuál el propósito es neutralizar, dañar o eliminar a sus rivales".

Estamos acostumbrados a ver los conflictos sociales como un enfrentamiento de comunidades contra empresas extractivas o el Estado, pero existen conflictos de otro tipo que no se entienden usualmente como 
tales. La violencia basada en género no suele entenderse como un conflicto social porque por muchos años ha sido un problema que se ha visto relegado al ámbito de la casa y lo privado.

Es un conflicto en el que se ven involucradas dos partes con ideas que contrastan: los agresores y las personas que se ven afectadas por la violencia. En este caso, si bien las afectadas directas son las mujeres que la sufren, las consecuencias repercuten también en sus hogares y comunidades, convirtiéndose el problema en uno más grande. Las ideas a contrastar en el caso de este conflicto tienen que ver con las relaciones de poder desiguales que existen entre hombres y mujeres en la sociedad. Aunque en teoría existe igualdad de derechos entre hombres y mujeres, en la práctica aún se enfrentan a brechas importantes que las dejan en posición de vulnerabilidad.

Por nombrar algunas, en el 2017 la brecha salarial en el Perú fue de 28.4\%, lo que significa que en promedio, por cada $\mathrm{S} / .1 .00$ que ganó un hombre, una mujer ganó S/.0.72. (INEI, 2018) A pesar de que en total entre trabajo remunerado y trabajo doméstico no remunerado, las muejeres trabajaron en promedio nueve horas más que los hombres a la semana. (INEI, 2017) Hay, además, un porcentaje importante de mujeres en el Perú que no reciben ingresos propios (31.5\%) (Observatorio Nacional de la Violencia Contra las Mujeres y los Integrantes del Grupo Familiar, 2019), lo que las hace dependientes económicamente de su pareja y las coloca en una posición de vulnerabilidad y poder disminuido.

En años recientes, la problemática de la violencia basada en género se ha ido trasladando de la esfera privada y el ámbito familiar, de verse como 
una situación que debería ser callada y escondida, a la esfera pública, donde se ha convertido en un problema que concierne a la sociedad.

Una mujer víctima de violencia es un problema no solo para ella misma y su familia, sino también para la comunidad en la que vive y se desenvuelve. A mayor escala, la violencia de género se convierte en una problemática que concierne a todo el país.

Según las definiciones expuestas previamente, podemos clasificar la violencia basada en género como un conflicto social. Se genera a partir de una situación de desigualdad, agravada por factores influyentes como crisis económica y ausencia del Estado que incrementan esta desigualdad, y es una lucha por poderes que tiene como intención final neutralizar a una de las partes; en este caso, los agresores ejercen violencia sobre las víctimas para que se mantengan siempre en esa posición de desigualdad y vulnerailidad y poder ejercer poder sobre ellas.

La violencia basada en género, además, afecta a una porción importante de la población, ya que repercute en las comunidades de las víctimas y no discrimina en cuanto a nivel socio económico, ubicación geográfica ni grupo etario; está presente en todas partes. La violencia basada en género atenta contra los Derechos Humanos de las víctimas, y las priva de la posibilidad de un desarrollo pleno, tanto a ellas como a la sociedad.

\subsection{Contexto}

\subsubsection{Realidad de la violencia de género en el Perú actual}

En el año 2018 se registraron en todo el Perú 149 casos de feminicidios (MIMP, 2019). En lo que va del 2019, se han registrado 53. En promedio, 
se calculan 10 víctimas al mes (Observatorio Nacional de la Violencia Contra las Mujeres y los Integrantes del Grupo Familiar, 2019). El feminicidio es el último paso en una sucesión de eventos violentos que van escalando, por lo tanto representa solamente una fracción de los casos de violencia.

La violencia basada en género (VBG) se manifiesta de distintas formas: psicológica, física, sexual y económica y todas se pueden ver en todo el país y en Lima Metropolitana. Al 2017, la prevalencia de la violencia por parte de la pareja en mujeres alguna vez unidas en Lima Metropolitana fue de 64.7\% (ENDES, 2017). La violencia psicológica fue la más prevalente $(61.6 \%)$, seguida por la física $(27.6 \%)$ y la sexual (4.9\%); ENDES no contempla la violencia económica. Aún con la magnitud de estos datos, no se llega a tener un panorama completo de la problemática.

Como ejemplo, en el 2017, el Centro de Emergencia Mujer (CEM) de Villa El Salvador registró 3006 casos, lo que representa un aumento de 40\% sobre el año anterior; es el CEM que presenta mayor cantidad de casos a nivel nacional. Y el CEM lleva solamente un registro parcial de los casos de violencia: una mujer tiene que ir a denunciar, lo que siginifica que tiene que estar dispuesta a denunciar y tiene que elegir el CEM como el espacio para hacer su denuncia o buscar ayuda. Es una combinación difícil de conseguir; al 2017, el 70.8\% de mujeres entre 15 y 19 años alguna vez unidas que sufrieron violencia por parte de su pareja o expareja no buscaron ayuda en ninguna institución. (ENDES, 2017)

Como parte de la búsqueda del Estado por erradicar la violencia basada en género, se han dado una serie de leyes y políticas nacionales que apuntan a reducir las desigualdades que exacerban la violencia y proteger a las 
víctimas. El 6 de noviembre de 2015 se promulgó la "Ley para prevenir, sancionar y erradicar la violencia contra las mujeres y los integrantes del grupo familiar, $\mathbf{N}^{\mathbf{0}}$ 30364." (El Peruano, 2015) Ley que contempla que se trabaje con los enfoques de igualdad de género, Derechos Humanos, integralidad, interculturalidad, interseccionalidad y generacional en la erradicación y prevención de la VBG.

En el 2016, se creó el Plan Nacional Contra la Violencia de Género 20162021, como continuación al Plan Nacional contra la Violencia hacia la Mujer 2009 - 2015, para crear instancias institucionales en los tres niveles de gobierno (local, regional y nacional) que regulen, sancionen $\mathrm{y}$ prevengan la VBG; con un espectro de protección más amplio que el plan anterior, con enfoque de género, interculturalidad, interseccionalidad, Derechos Humanos, etc.

Asimismo, el 4 de abril de este año se promulgó la Política Nacional de Igualdad de Género, que promueve la igualdad entre hombres y mujeres y busca disminuir o erradicar las brechas de desigualdad que existen entre ambos. De esta manera, el Estado trabaja en todas sus instancias para poder eliminar las desigualdades sistemáticas causadas por brechas estrcuturales, sacar a las mujeres de la posición de vulnerabilidad y poder dar un paso más adelante hacia la eliminación de la VBG.

La inclusión del enfoque de género en la currícula nacional escolar busca formar a los estudiantes en igualdad. Que reconozcan desde jóvenes temas de igualdad de derechos, estereotipos dañinos, igualdad de oportunidades y que así se pueda empezar a trabajar en la reducción de brechas desde el inicio de la educación. Una educación con igualdad significa desarrollo 
pleno para los estudiantes y esto apoya al desarrollo pleno, democrático e inclusivo de la sociedad.

\subsubsection{Villa El Salvador}

Villa El Salvador (VES) es, en la actualidad, el quinto distrito más poblado de Lima Metropolitana. Forma parte del área de Lima Sur, y tiene una extensión de $35.5 \mathrm{~km} 2$. Hacia el 2017, su población se acercaba a los 400 mil habitantes. La mitad de su población económicamente activa percibe ingresos menores a 270 dólares mensuales.

El distrito nació en el año 1971, cuando cientos de familias, en su gran mayoría migrantes del interior del país, llegaron a establecerse en un arenal a las faldas de un cerro en Pamplona. Un enfrentamiento, que terminó en muertes, con la policía en un intento de desalojo, y el apoyo de la Iglesia Católica a través del Monseñor Bambarén, convirtieron esta invasión en un caso importante y que había que solucionar. El 11 de mayo de 1971, los pobladores accedieron a ser reubicados a la Hoyada Baja de la Tablada de Lurín, donde nació por fin Villa El Salvador. (Amigos de Villa, 2019)

La historia de organización comunitaria de Villa El Salvador es resonada; es la forma a través de la cuál lograron construir ciudad del arenal y es una historia en la que las mujeres siempre fueron protagonistas.

En la década del 80, las mujeres que ya estaban organizadas en el Vaso de Leche, Comedores Populares y clubes de madres, crearon la FEPOMUVES, Federación Popular de Mujeres de Villa El Salvador, como forma de hacer que se reconociera el trabajo que venían haciendo por el desarrollo del distrito y poder hacer un trabajo concertado entre 
organizaciones para poder continuar con el mismo. Al año 1992, la FEPOMUVES constaba de 112 comedores populares y 507 comités del Vaso de Leche. (CVR, 2003)

Años después, el Colectivo de Concertación por la Equidad de Género nace como el sucesor espiritual de la FEPOMUVES (que sigue teniendo fuerte presencia en Villa El Salvador) y reúne a representantes de distintos colectivos del distrito que tratan temas de seguridad humana, formación política, igualdad de género, todo con la intención de cerrar las brechas que existen en el distrito.

\subsection{Diagnóstico de antecedentes}

\subsubsection{Representaciones de la mujer en productos mediáticos}

"Los medios de comunicación son capaces de instalar ideas de acuerdo a las transformaciones que se realizan en la realidad, también pueden reforzar imágenes tradicionales y roles estereotipados de cada quién.” (Cáceres, A., 2018)

Los medios de comunicación son en muchos casos, los responsables de ciertos patrones de comportamiento que los consumidores adoptan, formando su cosmovisión y percepción de la realidad a través de los ejemplos y productos que los medios generan. Es así que hay muchos niños y niñas que forman sus ideales de vida alrededor de ser como Nicola Porcella y Alejandra Baigorria, por ejemplo.

No son solamente los niños y niñas consumidores de estos productos, personas adolescentes y adultas también. Y si bien la cosmovisión y patrones de comportamiento de personas mayores ya están más formados y 
establecidos, si es que estos fueran, por ejemplo, la idea de que las mujeres son inferiores a los hombres por una cantidad de motivos, entonces podrían encontrar validación en los mismos medios que consumen y que empezaron la construcción de estas ideas tiempo atrás.

Los medios trabajan usualmente con tres arquetipos de mujer: La virgen, la madre y la mujer seductora (la María Magdalena). A través de la construcción de estos arquetipos, crean un estándar para lo que es aceptado para las mujeres y lo que no, una construcción de la normalidad de la mujer. (Prudencio, E. 2018)

Encontramos estos tres arquetipos en variedad de productos culturales, como la música, por ejemplo. Hablando específicamente de la cumbia peruana, "un medio que fortalece el sentido de pertenencia del poblador rural migrante dentro del proceso de integración cultural en la ciudad." (Prudencio, E. 2018). La cumbia nace a partir de una mezcla de ritmos, incluyendo fuertemente la influencia de música de los Andes, a partir del boom migratorio de población andina a la capital. Como producto cultural, la música suele representar en sus canciones la cosmovisión de la persona que la escribe. En este caso, encontramos que en las canciones de cumbia, están presentes los tres ejemplos de arquetipo de mujer: la virgen, la madre y la seductora. Cumplen una variedad de roles dentro del mundo de la música y las canciones: la mujer que canta a su amor, el amor a quién va dedicada la canción (en ambos casos la virgen), la mujer que entra a romper una relación (la seductora), la mujer que deja a su pareja y lo deja despechado, el culto a la madre, etc. A través de las letras de las canciones podemos apreciar cuáles son los roles tradicionales que se atribuyen a las mujeres en la comunidad que las genera. 
Por ejemplo, en el ranking de la emisora de Radio Nueva Q, especializada en cumbia, encontramos en el ranking top 10 canciones como "Mala" de Gran Orquesta Internacional, que dice "Tú eres mala, conquistaste mi corazón para nada, yo te di mi amor, pasión, mi corazón, fuiste mi sol, mi religión. Mala, mala te vas y no volverás y por las noches me vas a extrañar". La canción hace referencia a una mujer que corresponde al arquetipo de la mujer seductora, que hizo uso de sus encantos para conquistar al vocalista y luego lo dejó. Una mujer que merece sanción, de acuerdo con la calificación de valor de "mala" y la afirmación de que va a extrañar al cantante; que va a sufrir por sus acciones.

En el ranking de la Radio Nueva Q también encontramos la canción "La Roba Maridos" de Marisol. En esta letra, la cantante se identifica con el arquetipo madre (aunque no habla de relación parental, hace referencias a ser una señora, y toma el rol de una mujer con decisión, independencia) y se contrapone con la mujer seductora que es la roba maridos. "“Qué tiene ella? No puede compararse conigo, si yo soy una dama y ella es un caso perdido. ¿No lo ves? Es una cualquiera pues nada le cuesta. Por cuatro cervezas con cualquiera se acuesta". Nuevamente, se está haciendo una valoración negativa sobre la mujer seductora, calificativos como "una cualquiera" y "un caso perdido" se emplean para dejar en claro quién es la "mala" de la historia, aunque en este caso el marido en cuestión tenga tanta culpa (incluso más) como la mujer que lo sedujo. El castigo va para ella.

La televisión también es cómplice en la construcción de estas normalidades y estereotipos. Risas y Salsa fue uno de los programas cómicos con más rating en la historia de la televisión peruana, adaptando un formato argentino de sketches variados. El humor recaía principalmente en un nivel primario de comedia: el slapstick, que conlleva una gratificación 
inmediata, el chiste es el golpe y no hay más niveles que analizar. Además, hizo uso fuertemente de la representación estereotípica y caricaturizada de diversos personajes, como son el homosexual, el migrante rural ("el cholo"), el afroperuano, etc, para generar comedia a costa de percepciones incorrectas y exageradas de estos. Finalmente, Risas y Salsa incluyó la figura de la vedette en el círculo de la comedia. En el caso de la vedette, podemos observar que la construcción de su personaje toma del arquetipo de la virgen, en cuestión de inocencia (la pintan como tonta, crédula y fácil de manipular) y esto contrasta con su presentación visual, que toma del arquetipo de la mujer seductora: hace uso de su sensualidad y su cuerpo como carta de presentación (Cáceres, A., 2018). Esto la convierte en un producto de consumo fácil y masivo. Así, se perpetúa la figura de la mujer como objeto de consumo más que como sujeto de acción.

Una característica de los programas cómicos peruanos también es la representación del "criollismo", de la viveza. "El que no vive conchudo, muere cojudo" dice un dicho popular, que encapsula la esencia del criollismo y la viveza peruana. En relación a la construcción de la masculinidad, el criollismo se ve asociado a no "ser un pisado" o un "saco largo" (Cáceres, A. 2018). Un personaje que es vivo suele tener una esposa pero además tener interés por otras mujeres, quizás más jóvenes, atractivas, etc, porque busca tener lo mejor de todo. No concibe encontrar la felicidad plena con su esposa porque significaría que está renunciando a su viveza y eso lo convertiría en un "cojudo" o en un personaje menos masculino.

La idea de la masculinidad tóxica en relaciones de pareja se ve también en otro programa que tuvo muchísimo rating en la televisión peruana: Pataclaun. Pataclaun buscaba hacer sátira de distintos estereotipos: el cura pervertido, la hueca del Villa María, el ama de casa sumisa y el "Macho 
peruano que se respeta". Este último, Machín interpretado por Carlos Alcántara, estaba casado con Wendy (el ama de casa, arquetipo virgen) un personaje completamente maleable, influeciable y bueno. De buenas intenciones y buen corazón. La relación buscaba reflejar la realidad de muchas parejas en el Perú, donde la masculinidad tóxica, la virilidad como masculinidad no domesticable, impulsiva, la idea de hombría plena (Cáceres, A. 2018) gana por sobre el amor y la relación se vuelve abusiva; así, Machín con frecuencia golpeaba a Wendy (la "lapeaba"). Slapstick, que como en Risas y Salsa, se usaba para generar comedia. Aún más potente por el uso de efectos de cómic, de acuerdo con la estética del programa. A pesar de que lo que se hacía era una sátira, una crítica a la sociedad a través del humor, Machín nunca recibía sanción por sus comportamientos hacia Wendy, lo que hace que la crítica haya estado incompleta y que personas cuyos patrones de comportamiento ya estaban formados en esa dirección, los hayan podido ver reforzados a través del uso de la violencia como humor.

Las telenovelas, el producto de mayor consumo en Latinoamérica (Cáceres, A. 2018) también son culpables de la perpetuación de una normalidad percibida. En este caso, los arquetipos son más claros aún: la protagonista suele encajar en el arquetipo de la virgen. Es inocente, pura, de buen corazón y buenas intenciones, busca el amor verdadero y estas son las características que la hacen atractiva, que hacen que el espectador quiera que "gane". La antagonista suele ser la mujer seductora, la María Magdalena; probablemente busque conquistar al interés amoroso principal haciendo uso de su sensualidad en contraposición a la inocencia de la protagonista. En muchos casos se puede ver también el arquetipo madre, ya sea porque la protagonista pasa a ocupar ese rol como culminación de un arco amoroso fructífero o porque aparece la madre de alguno de los 
personajes, usualmente el interés amoros principal, para representar el modelo de mujer fuerte, con agencia y abnegada. En el caso de las telenovelas, las valoraciones asociadas con cada uno de los roles son mucho más explícitas. La virgen merece recompensa: vivir feliz para siempre con el amor de su vida, en muchos casos, salir de la situación de pobreza en la que se encontraba al inicio. Su contraparte, la seductora, merece sanción: muerte, un accidente que la deje paralizada, encarcelamiento, etc. Esto refuerza la idea de que el ideal es el rol tradicional de las mujeres: sumisas, sin agencia, que viven para el hombre que aman.

Las distintas construcciones de lo que es normal y aceptado en mujeres y hombres a través de los arquetipos de mujer y las relaciones representadas en productos mediáticos, aportan a la construcción de las relaciones interpersonales de quienes los consumen. Lo que se presenta como normal según los medios cala en lo que los consumidores perciben como normal en su realidad: emulan lo que consideran positivo y sancionan lo que se sale de esta. Al utilizar los productos mediáticos como insumo para la construcción de patrones de comportamiento y cosmovisión, se está aferrando en muchos casos a estereotipos negativos y exagerados, que terminan por hacer daño especialmente a las mujeres. Los estereotipos presentados, refuerzan la idea de que las mujeres tienen un rol positivo siempr ey cuando sean inocentes, sumisas, calladas y que la mujer con agencia (siempre y cuando no esté en el rol de madre) y que hace uso de su sensualidad y su cuerpo, que se reconoce como sujeto individual fuera de su relación, merece sanción.

\subsubsection{Informar sobre la violencia}


Cuando informamos sobre cualquier conflicto, hay una serie de consideraciones que hay que tener en cuenta para poder reflejar de la manera más fidedigna posible la realidad del conflicto, las intenciones y motivaciones de todas las partes implicadas y evitar que la comunicación se convierta en una herramienta para acrecentar el conflicto o construir un discurso que tergiverse los hechos.

En el caso de la VBG, hay inclusive otros factores que hay que considerar, tanto en tratamiento del episodio de violencia, como en el de la víctima. Según epecialistas en género del Programa de las Naciones Unidas para el Desarrollo (PNUD) en Perú, al momento de informar sobre el hecho, se debe conservar siempre la presunción de inocencia, dar a conocer el acto de violencia mas no el agresor, tener clara la tipificación del delito (diferenciar, por ejemplo, feminicidio vs. "Crimen pasional"), no minimizar ni justificar la conducta del agresor (no referirse a un arrebato, arranque de celos, depresión, etc.) y no ahondar en otras manifestaciones de violencia que el agresor haya ejercido sobre la víctima (amenzas, insultos, humillaciones, control de sus movimientos, control económico). En cuanto a la reconstrucción de los hechos, un exceso de detalle o primeros planos de lesiones causadas en la agresión, no aportan nada más que a crear morbo. (PNUD Perú, 2018)

Cuando hay que informar sobre las víctimas de la agresión, hay que reconocer que estas no responden a un patrón pre-determinado, no cuestionar su actividad ni la veracidad de su relato, no incluir referencias a su actividad económica, no facilitar la identidad de la víctima, imágenes de su domicilio, famila, amigos ni otros datos. (PNUD Perú, 2018) Hay que tener siempre en cuenta el contexto en el que se desenvuelven los 
protagonistas de la historia para poder entender de mejor manera, también, las motivaciones de sus actos o su inacción.

Se deben tener estas consideraciones al momento de informar para evitar generar una historia que pudiera perjudicar o arriesgar aún más a la víctima que podría aún encontrarse en situación de vulnerabilidad, revictimizarla, cuestionar su testimonio y echarle la culpa, o darle a los agresores el protagonismo que podrían estar buscando en el caso de eventos mayores.

\subsubsection{Micaela De Osma}

El 6 de octubre de 2017, Martin Camino Forsyth fue grabado por una vecina mientras arrastraba a su pareja en ese entonces, Micaela de Osma, por la calle en Miraflores y posteriormente por las escaleras del edificio donde vivían. Se encuentra recluído en el penal de Lurigancho desde el 14 de octubre del mismo año.

La información inicial que salió en los medios incluía casi en el 100\% de las notas, el video de la agresión. La noticia se contruyó alrededor del video captado por la vecina, siendo la palabra "VIDEO" la que abría o cerraba muchos titulares ${ }^{1}$.

"Mujer fue violentamente arrastrada y golpeada por sujeto en Miraflores [VIDEO] " - El Comercio, 9 octubre 2017

\footnotetext{
${ }^{1}$ Se eligieron los titulares de las plataformas digitales de los 6 medios con mayor lectoría (CPI, 2017) y prestigio del país. Se han elegido las plataformas digitales por la naturaleza de la noticia, que se generó a partir de una publicación de Facebook.
} 
"Facebook: Indignación por sujeto captado arrastrando a su pareja en plena calle [VIDEO]"-La República, 10 octubre 2017

“ ¡Justicia para Micaela! Arrastró a su pareja por toda la calle bajo amenazas [VIDEO]"-Perú 21, 8 octubre 2017

"Ni Una Menos: hombre arrastró por la calle y amenazó de muerte a su pareja en Miraflores [VIDEO]" - Correo, 9 de octubre de 2017

"Ni una menos: mujer fue arrastrada por la calle por un sujeto en Miraflores [VIDEO]" - El Trome, 9 octubre 2017

"Sujeto arrastra por las calles a su pareja y todo queda ¡registrado en video!" - Ojo, 9 octubre 2017

Las notas abrieron en su mayoría con la presentación del video ( o en el caso de La República, una composición con capturas del video) luego de la bajada. Utilizando las imágenes explícitas del episodio para captar la atención de los lectores. En este caso, por la naturaleza explícita de las imágenes, es imposible mantener la presunción de inocencia.

Toda la cobertura inicial del hecho incluye en la bajada o en el lead los nombres de ambos involucrados y denotan su relación sentimental. Inmediatamente después, el lead narra los hechos ocurridos: Que Camino Forsyth fue grabado mientras arrastraba a Micaela de Osma por la calle. Algunos medios (La República) dan mayor información sobre otros actos de violencia que habría tenido previamente Camino hacia De Osma, como amenazarla con un cuchillo. 
Todas las notas mencionan, ya sea en el titular, el cuerpo de texto o en los tags las palabras Ni Una Menos, alineando el caso al movimiento en contra de la violencia basada en género, que había cobrado mucha importancia el año anterior y días antes de la agresión había convocado a una marcha con motivo del Día de la Eliminación de la Violencia Contra la Mujer (25 de noviembre).

Más allá de informar netamente el hecho noticioso que es la agresión, algunos medios (El Comercio, Correo) también informaron sobre la experiencia de De Osma en el médico legista, a partir de una publicación suya en Facebook que decía que había tenido que esperar más de una hora para pasar. Además, incluyeron una publicación realizada por la hermana de Camino Forsyth, donde denunciaba las acciones de su hermano y declaraba que su familia no estaba de acuerdo y no lo iba a defender.

La República, incluyó en su nota declaraciones de la víctima detallando paso a paso cómo había ocurrido la agresión desde el momento en el que el agresor llegó a la casa; ahondando en detalles que quizás no eran necesarios para relatar el hecho noticioso.

Los medios continuaron con su cobertura de los hechos, siguiendo la sentencia de prisión preventiva de 9 meses a Camino Forsyth, así como las declaraciones posteriores de su abogado, argumentando que la tipificación del delito como intento de feminicidio era exagerada por la sentencia que conllevaba y que debería ser considerado por daño coroporal. Que había sido más "una humillación contra la mujer" (Perú 21, 2017). 
Hubo también cobertura a declaraciones posteriores de Micaela De Osma, sobre su relación con Camino Forsyth y los episodios violentos que se habían dado previamente en esta.

Hasta este punto, toda la cobertura tiene que ver casi directamente con el hecho noticioso original, la agresión del 6 de octubre. Ya sea a través de declaraciones directas de la víctima o la sentencia todo son consecuencias de la agresión.

El jueves 12 de octubre, la revista Caretas publicó una nota titulada "Patrones tóxicos"; en la bajada de la misma hacía referencia al padre de la víctima, que nada tenía que ver en el hecho noticioso que se reportó originalmente.

"Joven víctima de brutal agresión es hija de Miguel De Osma, sentenciado por sonado homicidio" (Caretas, 2017)

La nota empieza narrando la agresión, para luego desmentir declaraciones de De Osma sobre la violencia en su relación con Camino Forsyth (ella declaró que era la primera vez que la violencia llegaba a un punto físico, Caretas dice "No era tanto así como la primera vez. Hace dos años Camino Forsyth la agredió en la calle hasta hacerla caer y se resistió a los policías que intervinieron. El episodio quedó registrado solo como una ocurrencia, pues De Osma no presentó una denuncia"). Luego de deslegitimar las declaraciones de la víctima, la nota pasa a la pregunta "Con todos esos antecedentes, ¿por qué seguía Micaela con una pareja así?”.

Este cuestionamiento sugiere que Micaela De Osma tiene parte de culpa en la agresión que sufrió, por "seguir con una pareja así" después de haber 
habido indicios de que se trataba de una persona violenta. Así, la nota ignora por completo las complejidades de la violencia en una relación de pareja, las situaciones de poder desiguales y el componente psicológico de la problemática y continúa dándole fuerza a la idea común de que una mujer que es violentada tiene la culpa porque "le gusta" "es tonta" o "no se hace respetar".

Luego, hace una conexión entre lo que pasó con Micaela y Martin Camino Forsyth y el crimen por el que se sentenció al padre de ella, el asesinato de un vecino en 1997, 20 años antes que la agresión a De Osma. Lo que sugiere la redacción es que los patrones de violencia experimentados por Micaela en su niñez, la llevarían a buscar replicarlos en la adultez, por lo que seguiría con una relación violenta y abusiva. "El origen de un brutal video puede tener sus claves en el pasado." (Caretas, 2017)

Al hacer estas relaciones y cuestionamientos, el discurso que está perpetuando la revista indica que la víctima tiene la culpa: por no salir de una relación abusiva, porque eventos de su niñez sobre los cuáles ella no tenía ningún tipo de control le generaron la predisposición a entrar en relaciones tóxicas y buscarlas subconscientemente. Este discurso común está evidenciado en los comentarios que surgieron en la publicación original, como "Si no fuese por el video apuesto que ella hubiese callado. Se queja del sistema pero (no) es consciente que este pata tenía esa conducta porque no es la primera vez que la golpea. Tampoco te revictimices porque debiste denunciar en la primera ocasión que te agredió" (Trome, 2017) y "Esa mujer sola se busca su mal al vivir tanto tiempo al lado de el y lo denuncia solo cuando sale un video filmado por un tercero, de locos la sociedad de ahora." (Trome, 2017). 
Si nos regimos bajo los lineamientos establecidos previamente por el Programa de las Naciones Unidas para el Desarrollo en Perú, podríamos decir que la cobertura del hecho estuvo en todo momento, equivocada. Dando siempre detalles explícitos e innecesarios, ahondando en el pasado de la pareja y actos violentos previos, fortaleciendo la idea preconcebida de que la víctima de alguna manera tiene la culpa por conocer la situación y no salir inmediatamente de ella, ignorando lo complejo de la situación de violencia basada en género. También, dando información sobre la familia de la víctima y del agresor, que poco o nada tienen que ver con el hecho noticioso.

\subsubsection{Cindy Arlette Contreras}

El 12 de julio de 2015, las cámaras de seguridad de un hotel en Ayacucho captaron a Adriano Pozo (su pareja en ese entonces) arrastrando a Arlette Contreras del pelo por la recepción. Al igual que en el caso de Micaela De Osma, el caso se construyó alrededor del video que fue la evidencia; el video estuvo presente en la cobertura de medios. Las circunstancias de la agresión fueron el gancho para generar tráfico hacia la nota: resaltaron el hecho de que Adriano Pozo estaba desnudo al momento del episodio y que era hijo de un regidor de Ayacucho; llegaron a apodarlo "el agresor calato" (El Comercio, 2015) y “calato pegalón” (Correo, 2015).

"Joven desnudo agredió salvajemente a su ex pareja en hotel" El Comercio, 16 de julio 2015

"Hijo de regidor de Huamanga fue detenido. La fiscalía lo liberó y la PNP argumentó que hubo agresión mutua", 
"Ayacucho: Sujeto desnudo arrastró a su ex pareja en un hostal y fue detenido pero..." - Perú 21, 16 de julio de 2015

"Adriano Pozo, quien es hijo de un regidor de Huamanga, es el autor de esta cobarde agresión en contra de una joven mujer."

Pozo quedó en libertad poco tiempo tiempo después de la agresión, por la relación que existía entre su padre, el regidor Jorge Pozo y la fiscal Ítala Farfán. Sobre esto, se manifestó el Ministerio de la Mujer y Poblaciones Vulnerables, a través del asesor legal Víctor Medina, del Centro Emergencia Mujer (CEM) de Huamanga. (Correo, 2015) y la abogada Elizabeth Vásquez, que asumió la defensa de Contreras.

Farfán fue retirada del caso por la posibilidad de una opinión parcializada que beneficie a Pozo, así como los policías que atendieron la denuncia por considerar el episodio como "violencia común" y no tomar en cuenta el intento de violación ni homicidio, que agravaría el caso y la pena de Pozo.

Se reportó también sobre declaraciones del padre de Pozo, Jorge Pozo, diciendo de su hijo: "Adriano es un muchacho borderline, ha estado en tratamiento desde el año pasado. Por eso vino a estar cerca de mí, Ayacucho es más tranquilo. Pero conoció a esta señorita y su vida cambió. Ella presionaba para que haya dinero, reuniones. Él iba a terapia una vez por semana". (El Comercio, 2015)

Hay que resaltar en estas declaraciones que Pozo estaría sugiriendo que cualquier cambio en el comportamiento de su hijo, sería producto de su relación con Cindy Arlette Contreras, echándole la culpa indirectamente de su agresión. 
Las declaraciones de Pozo continuaron echándole la culpa a la víctima, sugiriendo que ella habría provocado la situación para buscar un beneficio económico. ““"Ella trabaja en una agencia de anfitriona, por eso siempre está buscando imagen, que su imagen se venda", refirióo." (El Comercio, 2015).

La publicación de estas declaraciones del padre de Adriano Pozo es innecesaria, ya que distrae la atención del hecho inicial, que es la agresión que sufrió Contreras, y si bien el medio no emite ninguna opinión a favor ni en contra sobre estas, el presentarlas como noticia ya está reforzando la idea de culpabilidad de la víctima en el imaginario colectivo. De nuevo, perpetuando el discurso de que la víctima de violencia busca ser agredida, o se lo merece.

La narrativa de la salud mental inestable del agresor es otra a tener en cuenta, que se vio reforzada por la publicación de los medios de las declaraciones de Jorge Pozo; al afirmar que su hijo estaba llevando tratamiento psicológico (no psiquiátrico) le quita parte de la culpa, y de alguna manera justifica su comportamiento violento con su condición psicológica. Otra justificación que se da, es que Pozo estaba ebrio y no recordaba nada de lo ocurrido. Así, se construye la idea de que Pozo estaba completamente fuera de sí, con un trastorno mental (trastorno límite de personalidad) y además, alcoholizado, entonces, al no estar consciente, no puede ser completamente responsable por sus acciones al momento de agredir a Contreras.

El 4 de agosto de 2016, tras ser liberado luego de 11 meses de prisión, Adriano Pozo concedió una entrevista a la revista Caretas. Caretas lo hizo portada de ese número. En la entrevista, titulada "Pozo sin fondo", Pozo 
niega las acusaciones de intento de violación y feminicidio, declara haber llegado al punto de arrastrar a Contreras del pelo por "frustración” y celos. Declara que "yo le abrí todo mi mundo. Ella estaba en reuniones familiares, podía utilizar mi celular, entraba a mi correo y a mi Facebook." Y luego que Contreras lo confundió con otro hombre, pintando una imagen de una mujer fría que lo manipuló; dice además que ella al confundirlo con otro, también lo agredió. Finalmente, Pozo dice que, aunque él lo creyó, nunca hubo amor entre ellos, que Arlette estaba solamente tras su dinero, porque "pidió una reparación civil de S/.500 mil" (Caretas, 2016).

Así, le dieron un espacio protagónico al agresor, que por las evidencias contra él (el video), era definitivamente culpable y no podía mantener ninguna presunción de inocencia, para que pueda defenderse y tergiversar la narrativa a su conveniencia. Fortalecer la idea de que Arlette Contreras había hecho algo malo al ir tras una persona "que le abrió su corazón" solamente por beneficio económico.

\subsubsection{Eyvi Agreda}

El 24 de abril de 2018, un hombre desconocido se subió a un bus en Miraflores, en el cruce de las avenidas Paseo de la República y 28 de Julio, y prendió fuego a una mujer, con combustible que llevaba en una botella de yogurt. Además de la agredida, hubo varios heridos que fueron trasladados al hospital Casimiro Ulloa. Se identificó a la mujer como Eyvi Ágreda, de 22 años.

Se captaron fotos y videos del momento en el que el chofer del bus intentaba ayudar a Eyvi, rociándola con un extintor. Las fotos y video se utilizaron en algunos titulares para enganchar a los lectores. 
"Sujeto quemó a mujer dentro de bus en Miraflores y testigo da detalles: "Estaba como antorcha humana" (VIDEO)" - Ojo, 25 de abril de 2018

"Miraflores: hombre prendió fuego a una joven al interior de un bus [VIDEO Y FOTOS]" - La República, 25 de abril de 2018

"Miraflores: Sujeto prendió fuego a mujer al interior de bus" - $\underline{E l}$ Comercio, 25 de abril de 2018

Las notas fueron actualizando a lo largo del día con información sobre el estado de Eyvi: que había sufrido quemaduras en el $70 \%$ del cuerpo, que había ingresado a la sala de operaciones para limpieza de las heridas, que ya se encontraba estable.

No había aún un sospechoso, así que los medios no reportaron inmediatamente sobre esto, pero sí sobre la posición del Ministerio de la Mujer de juzgar al culpable por intento de feminicidio, que lleva una pena máxima de 25 años.

Cuando encontraron al culpable, Carlos Javier Hualpa Vacas y este se declaró culpable (luego de haber negado varias veces haber sido él), sus declaraciones llevaron a un giro en la narrativa que se manejaba en la esfera pública. Hualpa declaró haber estado planeando "darle un escarmiento". (Trome, 2018) Había estado acosando a Eyvi por meses antes de atacarla, según declaraciones de la hermana de Ágreda, y al recibir negativa de la joven, empezó a planear su venganza. Él "solo quería desfigurarla" (Trome, 2018). 
El hecho de que la agresión hacia Ágreda hubiera sido tan violenta, y luego la frialdad con la que Hualpa habló de sus planes y motivaciones llevó a las personas a hablar de enfermedad mental, porque una persona sana no podría haber cometido el acto premeditado de la forma que se hizo. Esta idea se vio reforzada por la difusión del perfil psicológico del agresor a través de los medios y declaraciones de su abogado de que Hualpa había buscado ayuda en sus amigos y un pastor y no la había recibido.

"Javier Hualpa tiene alta motivación al rencor y al odio" - Ojo, 27 de abril de 2018

"Carlos Javier Hualpa Vacas: Su abogado dice que antes de atacar a Eivy Ágreda buscó ayuda en un pastor” - Trome, 27 de abril de 2018

De esta manera, la conversación acerca de la epidemia de salud mental en el Perú empezó a surgir entre el público. El discurso, dañino, de que los agresores tenían que ser personas con trastornos mentales, distraía la atención del problema central y el motivo real por el cuál se había dado la agresión: el machismo y la idea que había tenido Hualpa de que tenía que castigar a Ágreda por no haber recibido sus atenciones, que ella se merecía un castigo por no demostrarle reciprocidad. Además, perjudicaba también a las personas con trastornos mentales, pintándolas como agresivas y peligrosas.

En este caso, el Ministerio de Salud (MINSA) declaró pronto, intentando zanjar la discusión y aclarando que si bien podía haber coincidencias, no 
indicaba causalidad. Los medios rápidamente difundieron las declaraciones del MINSA.

"Minsa: Asociar las enfermedades mentales con violencia es "falso y cruel" - Correo, 26 de abril de 2018 / El Comercio, 27 de abril de 2018

"Según director de Salud Mental del Minsa, casos de violencia contra las mujeres responden a factores como el machismo y no a enfermedades mentales" - Correo, 26 de abril de 2018

"Colegio de Psicólgos del Perú: "La mayoría de agresores no tienen trastornos mentales" (VIDEO)" - Correo, 25 de abril de 2018

"No necesitas ser enfermo mental para cometer atrocidades" Correo, 04 de junio de 2018.

"Especialista indica que peruanos no van al psicólogo por vergüenza. Males mentales no se relacionan con la violencia."

Eyvi Ágreda murió en el hospital luego de un poco más de un mes de luchar por su vida. Hualpa fue trasladado a un penal en Cerro de Pasco.

Los medios fueron un aliado importante para desviar el discurso errado de que los agresores eran personas con trastornos mentales. Se hizo énfasis en que el origen de la violencia basada en género es el machismo y las desigualdades estructurales que existen entre hombres y mujeres y que es una idea que hay que erradicar. También fue acertado el manejo de la información al inicio, manteniendo la suposición de inocencia de Carlos Javier Hualpa hasta que él mismo confesó, no difundiendo información 
innecesaria sobre Eyvi y su familia y hablando del acoso que sufrió por meses como eso mismo, no como una justificación para la agresión. 


\section{PROPUESTA DE COMUNICACIÓN}

\subsection{Estrategia (Anexo 1)}

\subsubsection{Periodo de la estrategia}

La Estrategia está diseñada para implementarse durante el mes de noviembre del año 2019, empezando desde el lunes 4 al lunes 25 de noviembre, Día Internacional de la Eliminación de la Violencia contra la Mujer.

\subsubsection{Objetivo general del producto}

Informar al público sobre la problemática de la violencia basada en género en el Perú, y específicamente en Villa El Salvador; cómo afecta a las víctimas y sus redes de apoyo y dar a conocer iniciativas comunitarias que ya existen para erradicarla.

\subsubsection{Objetivos específicos}

- Informar sobre realidad e impacto de la violencia basada en género en el Perú y Villa El Salvador.

- Resaltar la importancia de la prevención en la erradicación de la violencia basada en género.

- Resaltar las iniciativas de las organizaciones comunitarias de Villa El Salvador.

\subsubsection{Mensaje principal}

Para erradicar la violencia contra las mujeres y niñas es fundamental poner el énfasis en la prevención. Fortalecer los esfuerzos en marcha, innovar en la práctica, fortalecer la inversión; tomando en cuenta los esfuerzos ya realizados por las redes de apoyo comunitarias. 


\subsubsection{Público objetivo}

- Sociedad civil:

Hombres y mujeres entre 18 y 44 años que sean usuarios de redes sociales. Con interés en temas de desarrollo e igualdad de género. Podrían describirse de manera general como millennials, generación que abarca desde el 1981 al 1995, personas entre las edades de 38 años y 24 . Conforman el $21 \%$ de la población del Perú y la mitad de ellos se encuentran en Lima. Buscan verse involucrados emocionalmente con los productos y marcas que consumen, generar un vínculo afectivo que hace que la marca cobre importancia y que ellos se sientan más conectados. (IPSOS, 2018) Prefieren una marca que tenga un compromiso con la sociedad y que tenga prácticas responsables y sostenibles, aunque no estén tan involucrados con el cambio social como sus sucesores de la Generación Z (IPSOS, 2018.) El uso de personas reales como voceros de la "marca" (en este caso de las iniciativas y la información) los atrae a seguir consumiendo el producto.

- Contrapartes, donantes y tomadores de decisión relacionados con el trabajo del Programa de las Naciones Unidas para el Desarrollo en el Perú. Hombres y mujeres entre 35 y 65 años, trabajadores de los poderes Ejecutivo, Lesgislativo, Judicial o algún organismo autónomo con alcance nacional. Perfiles profesionales en su mayoría con grado de magister. (PNUD, 2018)

\subsubsection{Canales de difusión}

La propuesta será difundida a través de las redes digitales del Programa de las Naciones Unidas para el Desarrollo (PNUD) en Perú; compuestas por dos grandes elementos: 
- Redes sociales (Facebook, Twitter, Instagram y Exposure)

- Web official de PNUD Perú (http://pe.undp.org)

La propuesta se alojaría en la web oficial de PNUD Perú, (como en este ejemplo de UNDP global). Estar en la web de PNUD y no en otro medio como Exposure (una plataforma que usa la organización para contar historias a manera de crónica, con especial enfoque en los personajes y en las fotos) le da a la propuesta la ventaja de poder ser replicada en los canales de UNDP a nivel global, como los boletines que se hacen llegar semanalmente a todas las oficinas país alrededor del mundo; lo que le daría mayor difusión a nivel tomadores de decisión.

Las redes sociales son un canal de difusión importante en el caso de mensajes de consumo masivo. Según IPSOS, el 85\% de adultos jóvenes el en Perú se conectan a internet por lo menos una vez por semana, y el 78\% usa redes sociales. El 98\% de personas con cuentas de redes sociales tiene cuenta en Facebook, 24\% en Instagram y solo $10 \%$ en Twitter (IPSOS, 2018) (aunque este es un porcentaje bajo, Twitter es una red importante para la estrategia por el tipo de público que hace uso de ella). E1 75\% de las actividades que se asocian con el uso de redes sociales e internet es de indagación, para los usuarios peruanos (IPSOS, 2018). De acuerdo con esto, la estrategia planea diseminar información relevante, cualitativa y cuantitativa sobre el problema de la violencia basada en género.

Por la forma en cómo se utilizan los medios digitales de PNUD, la red más importante a destacar vendría a ser Facebook, ya que es el medio con el mayor alcance, que va dirigido a un público objetivo más amplio. En este caso, hombres y mujeres de 18 a 44 años (principalmente) con interés en 
temas de desarrollo sostenible, reducción de las desigualdades, igualdad de género, etc. Facebook es el único medio en el que se consideraría una pauta publicitaria, para poder incrementar aún más el (buen) alcance orgánico que ya tienen los contenidos de PNUD Perú. Las publicaciones en Facebook serían menos y más estratégicamente elegidas que en el resto de redes sociales. Una a dos publicaciones como máximo por semana para que el tiempo de vida de la publicación sea amplio, que el contenido pueda ser consumido la mayor cantidad de tiempo posible y que la inversión en pauta publicitaria se utilice de la mejor manera. Los contenidos que se publicarían en Facebook serían el video testimonial, la infografía y gráficas, con enlace a la historia en la web PNUD. Los horarios de publicación varían de acuerdo al contenido: Para materiales gráficos como infografía, las 12 del día es un buen horario para las redes de PNUD, suelen tener un buen rebote, en el caso del video, es un contenido que requiere más tiempo para ser consumido, por lo que las 8:00 p.m. es la hora indicada, de acuerdo a experiencias previas.

Se publicarían también mensajes en Twitter, buscando alcanzar a las contrapartes principales de PNUD; tomadores de decisiones, donantes, aliados en la implementación, como el Ministerio de la Mujer y Poblaciones Vulnerables (que supervisa la implementación y funcionamiento de los CEM), Ministerio de Desarrollo e Inclusión Social, Presidencia del Consejo de Ministros, tomadores de decisiones aliados dentro del Congreso de la República como Tania Pariona y gobiernos locales, como la Municipalidad de Lima, Municipalidad de Villa El Salvador, etc. El horario de publicación en Twitter es menos específico: el algoritmo es más benevolente que el de Facebook y es más fácil tener mayor llegada al público sin la necesidad de invertir en una pauta publicitaria. Todas las publicaciones, sin embargo, deberían hacerse antes 
de las 5:00 p.m. hora Perú, para poder garantizar que todos los mensajes que se envíen tengan la posibilidad de llegar a las contrapartes propuestas, y a la sede de UNDP a nivel global; así, facilitar el rebote del contenido y la diseminación de los mensajes a través de contrapartes y aliados.

Finalmente, el Instagram serviría a través del uso de historias para mantener el tema vigente a lo largo de la duración de la estrategia, comunicar datos estadísticos de manera rápida, y enlazar a la propuesta en la web oficial. El público objetivo al que llega Instagram es similar al de Facebook, pero el rango de edad es más reducido (18 a 34 años). También existe interacción dentro del Sistema de Naciones Unidas a través de Instagram.

Los contenidos difundidos en las tres redes (Facebook, Twitter e Instagram), que serían diseñados específicamente para cada una de estas, con los distintos públicos objetivos en mente, tendrían, además de informar con datos puntuales, la finalidad de enlazar a la propuesta en la web de PNUD.

El PNUD en Perú tiene muy buena relación con medios tradicionales de comunicación; en el 2018, tuvo alrededor de 35 publicaciones gratuitas en diarios de alcance nacional como El Comercio, La República, El Peruano, Perú 21, rebote en la web de Andina, valorizados en más de medio millón de soles por espacio obtenido (PNUD Perú, 2019) además de visibilidad en medios internacionales como Planeta Futuro del diario El País, y la agencia EFE. Se buscaría capitalizar en estas relaciones con medios para dar mayor cobertura a la temática a lo largo de la estrategia, establecer entrevistas con expertos en el tema, columnas de opinión, etc. Además, se buscaría una alianza con La Mula (por una similitud en públicos objetivos 
en medios digitales) para posicionar la propuesta dentro de la plataforma Mujeres Que Transforman (MQT), que ya antes ha resaltado historias de mujeres relacionadas con proyectos promovidos por PNUD Perú.

\subsubsection{Financiamiento}

La propuesta será financiada por el componente de comunicación del Proyecto Justa: Villa El Salvador por la Justicia y la Igualdad, del Programa de las Naciones Unidas para el Desarrollo en Perú, que es financiado por el Gobierno de Corea; en alianza con el BBVA Continental, que viene trabajando temas de igualdad de género como un aliado desde el sector privado de la organización desde el 2019. BBVA además, ya ha trabajado de manera coordinada con el Proyecto Justa específicamente.

\subsubsection{Contenidos}

\section{Mujeres y Arena}

Mujeres y Arena es una historia que relata la realidad de la violencia basada en género en el distrito de Villa El Salvador, cómo afecta a las víctimas y sus redes de contactos y presenta a algunas de las mujeres que, desde distintos frentes, ya están trabajando con la comunidad para erradicarla y poder construir desarrollo inclusivo, sostenible y libre de violencia.

Tomará la forma de un website Onepage, como otras historias destacadas de UNDP para días importantes, donde la información va apareciendo conforme se va deslizando hacia abajo en la página.

Los contenidos estarán divididos en cuatro partes: 
1. Villa El Salvador: Una introducción breve al distrito para quienes no conozcan su historia o quieran refrescarla. Hará énfasis particular en el tejido social de VES, fundamental en la construcción y desarrollo del distrito, que será importante recordar más adelante. Presentará también algunos datos demográficos para poder conocer el contexto en el que se desarrollan las historias posteriores y los casos de violencia basada en género.

2. La Violencia: Presentará datos estadísticos obtenidos de diversas fuentes (Observatorio Nacional de Violencia Contra la Mujer e Integrantes del Grupo Familiar, ENDES, MIMP, investigaciones PNUD) que reflejen la realidad actual de la VBG en el Perú; cuántas mujeres sufren violencia, cuál es el tipo de violencia más común, cuál es el porcentaje de denuncias, etc. Luego, presentará data más específica sobre la situación en VES.

3. El Costo: Un acercamiento a la problemática de la VBG desde el enfoque económico. ¿Cuánto le cuesta a una comunidad responder a la violencia basada en género? Presentará información sobre gasto real, deudas, costo oportunidad, que debió asumir la comunidad de Villa El Salvador en el año 2018 como respuesta a la VBG; gastos que podrían evitarse o disminuirse a través de la inversión en prevención.

En este punto, hay que resaltar el enfoque novedoso de el costo económico aplicado a la violencia. Si bien ya se han hecho estudios similares a nivel empresa, es la primera vez en el Perú que se hace un estudio de este tipo a nivel distrital. De esta manera, se puede ver 
cuantitativamente el impacto económico de la violencia basada en género sobre la comunidad, que a gran escala, se podría usar para representar el impacto económico de la violencia a nivel país. La mayoría de los impactos económicos de la violencia suelen pasar desapercibidos o no suelen ser registrados como tales, por lo que tener esta información clasificada como lo que es aporta a ver la necesidad importante de inversión en prevención de violencia, que muchas veces no se hace por el costo que esto implica. Ver comparativamente el costo de la inversión en prevención y el costo de la respuesta desde las comunidades facilita la toma de decisiones al tener un panorama real del impacto. La inversión inmediata en la prevención aportará a la eliminación de la violencia a mediano y largo plazo y permitirá además que los costos no se sigan elevando. (Vara, A. 2018) "Medir los costos de la VBG constituye una necesidad para fortalecer los argumentos de prevención desde diversos sectores y niveles de gobierno." (Vara, A. 2018).

4. Las Mujeres: Las historias de cuatro mujeres de Villa El Salvador miembros de organizaciones comunitarias (El Colectivo de Concertación por la Equidad de Género, PAZOS Arte para la Educación y la escuela de formación política Mujeres de Arena) que representan diferentes enfoques y diferentes grupos generacionales que están trabajando constantemente por el empoderamiento de las mujeres de VES, para poder sacarlas de sus situaciones de vulnerabilidad y ayudarlas a salir del círculo de violencia.

\section{Gráfica}

La propuesta gráfica es simple. La paleta consta de dos colores: 


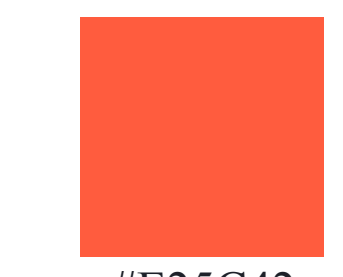

\#E25C42

R:226 G:92 B:66

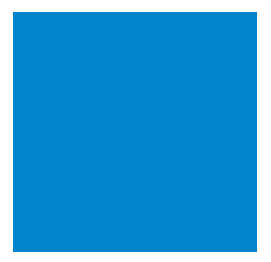

\#2884C9

R:40 G:132 B:201

Que se utilizan como colores para resaltar la data importante en el texto, sea en la gráfica de datos estadísticos o en las sumillas.

La tipografía que se emplea es Georgia, en sus pesos regular, bold y bold italic para hacer énfasis en ciertas partes del texto.

Hay poco uso de fotografías, es principalmente gráfica vectorial. Los retratos de las mujeres van en blanco y negro para poder mantener armonía con la paleta de colores limitada que se maneja, y están intervenidos con gráfica en los dos colores de la paleta para mantener cohesión y que no se vea aburrido.

Los datos estadísticos, sumillas y gráfica que resalte, se van a hacer en animación simple, para darle dinamismo al site y romper con la línea minimalista.

Los contenidos gráficos para redes sociales seguirán los mismos lineamientos gráficos.

\section{Contenidos complementarios}

La propuesta (Mujeres y Arena) se plantea como el contenido principal de la estrategia, que engloba todos los objetivos y mensajes que se quieren 
transmitir. A partir de este contenido "madre", se generarán contenidos para las distintas plataformas que se plantean para la difusión.

Para Redes Sociales (Facebook, Twitter, Instagram, Exposure):

- Pastillas gráficas con datos estadísticos para redes sociales.

- Fotos intervenidas con partes de historia o data.

- Animaciones cortas con data.

- Infografía sobre la situación de la VBG en el Perú.

- Historias de mujeres protagonistas (Berta Jáuregui del Colectivo de Concertación por la Equidad de Género, Jessenia Cutipa de PAZOS Arte para la Educación y Elisabeth Vargas de Mujeres de Arena) en texto y en video.

Medios de comunicación:

- Artículo de opinión: Invertir en prevención.

- Entrevista con expertos PNUD en el tema (Representante Residente del PNUD o con el Punto Focal de Género del PNUD en el Perú).

- Historias de mujeres protagonistas (Berta Jáuregui del Colectivo de Concertación por la Equidad de Género, Jessenia Cutipa de PAZOS Arte para la Educación y Elisabeth Vargas de Mujeres de Arena) en texto $y$ en video en plataforma Mujeres Que Transforman.

Otros:

- Taller con periodistas: ¿Cómo informar sobre la violencia basada en género? 


\section{RECOMENDACIONES}

El jueves 9 de mayo creé un grupo cerrado en Facebook con 30 de mis contactos. A continuación, puse el PDF para descarga y un álbum de fotos con las páginas independientes en orden de lectura para que pudieran revisar la propuesta de Mujeres y Arena (aclarando que se trataría de una web Onepage). Los comentarios fueron en su mayoría positivos y las sugerencias sobre contenido, orden de la información, diseño y usabilidad se aplicaron para poder mejorar la experiencia del usuario de la plataforma. A continuación, una compilación de los comentarios que se recibieron sobre la propuesta original:

\section{General:}

- ¿Has considerado tener un menú arriba para dar un enlace directo a cada capítulo? Porque te podrías perder en cada capítulo en el scroll."

- "Está muy claro el orden en el que se presentan las cosas."

- "Me impresiona el trabajo de investigación que se ha hecho."

- "En general, la información que presentas es precisa para entender el tema. Los datos y cifras al igual que los cuadros son una gran ayuda para entender mejor el problema. Ayudan bastante a contextualizarlo con la realidad del país."

- "Es bonito el layout, bastante amigable."

- “Vas a incluir alguna reflexión sobre un camino para trabajar una solución?”

- "Muy buen contenido y bien resumido. La gráfica me parece muy buena y pertinente." 


\section{Villa EI Salvador:}

- "Introducción, importante contextualización del problema y sus personajes."

- "Me gusta cómo encuadras el tema, la idea de levantar y construir un distrito y una comunidad desde la arena y la lucha por una sociedad "justa” en una ciudad hostil e infértil."

\section{La Violencia:}

- "Al inicio me confundieron un poco los datos sobre el incremento de feminicidios año a año. De repente puedes poner una gráfica para que sea más claro.”

- "Tal vez poner un gráfico de barras en vez de los números, para que la diferencia de datos se vea gráficamente."

- "Simple y al punto, ¿no sé si convendría agregar bibliografía aquí? Antes ya mencionas fuentes, pero en todo tipo de presentación es conveniente tener la fuente de todos los datos."

- "Todos los cuadros me parecen buenos."

\section{El Costo:}

- "Las siglas VBG y VES me confunden."

- “¿VBG es Violencia Basada en Género? No he visto el término completo en las anteriores láminas, espero que no se me haya pasado. La primera vez que uses cada término, ponlo completo con las iniciales entre paréntesis y a partir de allí, usa solo las iniciales, aunque sean términos obvios. Los textos académicos suelen usar ese método. Recomiendo eso para VES, VBG y CEM."

- "La última diapo me parece fundamental, porque presenta muy claro toda la información previa del capítulo." 


\section{Las Mujeres:}

- "Me gusta cómo se presentan las historias de las mujeres al final"

- "Definitivamente lo que más me gusta son estas introducciones."

- "Está todo bien presentado, con sus títulos, nombres, fotos, textos y citas. Entiendo la historia de cada mujer con el distrito y su papel en la lucha por mejorarlo."

- "El resaltado se ve un poco raro acá, gráficamente. Lo dejaría solo en negritas."

- "Trata de agregar algún punto más de color, como un resaltado. Es la única lámina de texto que no lo tiene y queda un poco triste."

- "Al final está bien expuesta la respuesta de las mujeres de Villa El Salvador. Muy bien presentado desde personas reales."

A partir de los comentarios, se hicieron cambios en la propuesta. Los más importantes son la inclusión de un botón de menú permanente en la esquina superior derecha de la página (como en la portada) para facilitar la navegación entre capítulos; y la inclusión de un quinto capítulo, La Respuesta, que incluya información sobre las iniciativas que ya existen desde el Estado a nivel de políticas públicas para eliminar la violencia basada en género y promover la igualdad, como la Política Nacional de Igualdad de Género, y la "Ley para prevenir, sancionar y erradicar la violencia contra las mujeres y los integrantes del grupo familiar, $\mathbf{N}^{\mathbf{0}}$ 30364." 


\section{REFERENCIAS}

ACNUR Comité Español. (2018). Qué es un conflicto social y qué efectos puede tener. 12 de mayo del 2019, de ACNUR Sitio web: https://eacnur.org/blog/conflicto-social-que-es-y-efectos/

Ágata Cristina Cáceres Sztorc. (5 de mayo de 2018). Perspectiva de los roles de género y sus representaciones en la televisión peruana. Análisis de casos emblemáticos desde 1980 hasta 2010. Revista ambios y Permanencias Grupo de Investigación Historia, Archivística y Redes de Investigación, 9, 232 263. Junio 2019, De Academia.edu Base de datos.

Alberto, J.. (2015). Sala de apelaciones reafirma prisión para "calato pegalón" durante audiencia. 12 de mayo del 2019, de Correo Sitio web: https://diariocorreo.pe/edicion/ayacucho/sala-de-apelacionesreafirma-prision-para-calato-pegalon-durante-audiencia-608481/

Amigos de Villa. (-). Historia de una ciudad: Villa El Salvador, Lima - Perú. 12 de mayo del 2019, de Amigos de Villa Sitio web: http://www.amigosdevilla.it/historia/cronologia01.html

Caballero, V. (2009). "Los conflictos sociales y socio - ambientales en el sector rural y su relación con el desarrollo rural" . 12 de mayo del 2019, de Sepia Sitio web: http://www2.congreso.gob.pe/sicr/cendocbib/con3_uibd.nsf/71267BC7FE0F83FA05257966007877E5/\$ FILE/Los_conflictos_sociales_y_socioambientales.pdf

Caretas. (2017). Patrones Tóxicos. 12 de mayo del 2019, de Caretas Sitio web: http://caretas.pe/sociedad/80506-patrones_toxicos

Christensen, C., Skok, D., \& Allworth, J. (2012). Breaking News, Mastering the art of disruptive innovation in journalism. Nieman Reports, (3), 6-20. Desde: https://niemanreports.org/wpcontent/uploads/2014/04/be the disrutpor.pdf

Chuchón, H.. (2015). Temo por mi vida, porque intentó matarme. 12 de mayo del 2019, de Correo Sitio web: https://diariocorreo.pe/edicion/ayacucho/temo-por-mi-vida-porque-intento-matarme-602985/

Comisión de la Verdad y la Reconciliación. (2003). LOS ASESINATOS DE MARIA ELENA MOYANO (1992)Y PASCUALA ROSADO (1996). En Informe Final(611). Perú: CVR.

Correo. (2015). Minsa: Asociar las enfermedades mentales con violencia es "falso y cruel" (VIDEO). 12 de mayo del 2019, de Correo Sitio web: https://diariocorreo.pe/peru/minsa-el-95-de-las-victimas-deviolencia-son-mujeres-815718/

Correo. (2018). Mimp denunciará por presunta tentativa de feminicidio a agresor de muchacha en bus. 12 de mayo del 2019, de Correo Sitio web: https://diariocorreo.pe/edicion/lima/mimp-denunciara-agresorque-quemo-joven-en-un-bus-por-presunta-tentativa-de-feminicidio-815374/

Correo. (2018). Colegio de Psicólgos del Perú: "La mayoría de agresores no tienen trastornos mentales" (VIDEO). 12 de mayo del 2019, de Correo Sitio web: https://diariocorreo.pe/edicion/lima/colegio-depsicolgos-del-peru-la-mayoria-de-agresores-no-tienen-transtornos-mentales-video-815535/

CPI. (2017). ESTUDIO DE LECTORÍA DE DIARIOS EN LIMA Y 15 PRINCIPALES CIUDADES. Lima: CPI.

Crespo, S.. (2016). Pozo Sin Fondo. 12 de mayo del 2019, de Caretas Sitio web: http://www2 caretas.pe/Main. asp?T=3082\&S=\&id=12\&idE=1271\&idSTo=0\&idA=76351\#.XNj94tNKiL J 
El Comercio. (2018). Eyvi Ágreda: Carlos Hualpa habla tras muerte de su víctima. 12 de mayo del 2019, de El Comercio Sitio web: https://elcomercio.pe/lima/judiciales/eyvi-agreda-carlos-hualpa-habla-muertevictima-noticia-528865

El Comercio. (2015). "Mi hijo es borderline, estaba ebrio y no se acuerda de nada". 12 de mayo del 2019, de El Comercio Sitio web: https://elcomercio.pe/peru/amazonas/ayacucho/mi-hijo-borderline-ebrioacuerda- 180750

El Comercio. (2015). Agresor dice ser borderline: ¿Qué es esto?. 12 de mayo del 2019, de El Comercio Sitio web: https://elcomercio.pe/peru/amazonas/ayacucho/agresor-dice-borderline-esto-181330

El Comercio. (2017). Mujer fue violentamente arrastrada y golpeada por sujeto en Miraflores [VIDEO]. 12 de mayo del 2019, de El Comercio Sitio web: https://elcomercio.pe/lima/sucesos/mujerviolentamente-arrastrada-golpeada-sujeto-miraflores-noticia-464167

El Peruano. (2015). LEY PARA PREVENIR, SANCIONAR Y ERRADICAR LA VIOLENCIA CONTRA LAS MUJERES Y LOS INTEGRANTES DEL GRUPO FAMILIAR. 12 de mayo del 2019, de El Peruano Sitio web: https://busquedas.elperuano.pe/normaslegales/ley-para-prevenir-sancionar-yerradicar-la-violencia-contra-ley-n-30364-1314999-1/

Eunice Prudencio Sotelo. (2018). "Ella es una mala... Ella es un amor" Representaciones de feminidad en la cumbia peruana. En Género en el Perú. Nuevos enfoques, miradas multidisciplinarias. (105 - 133). Lima: Universidad de Lima.

La República. (2017). Facebook: Indignación por sujeto captado arrastrando a su pareja en plena calle [VIDEO]. 12 de mayo del 2019, de La República Sitio web: https://larepublica.pe/sociedad/1107976miraflores-denuncian-cobarde-agresion-fisica-contra-una-mujer-

video?fbclid=IwAR3GYhuidCqT7dIQZGeIMPowC32tvxZt_D_rNQKDNXnvuaRyacUDqLD-HGc

Las Voces del Perú: Iniciativas de diálogo entre el Estado y el ciudadano. (2016). Lima: Tres Mitades.

Ministerio de Agricultura y Riego. (2019). Política Nacional de Igualdad de Género. 12 de mayo del 2019, de Gobierno del Perú Sitio web: https:/www.gob.pe/institucion/minagri/noticias/27222-politicanacional-de-igualdad-de-genero

Observatorio Nacional de Violencia contra las Mujeres y los Integrantes del Grupo Familiar. (2019). Datos y evidencias sobre violencia hacia las mujeres y a los integrantes del grupo familiar según fuente de información. 12 de mayo del 2019, de Observatorio Nacional de Violencia contra las Mujeres y los Integrantes del Grupo Familiar Sitio web: https://observatorioviolencia.pe/datos/

Peixoto Caldas, José Manuel y Rodríguez Castro, Yolanda. Violencia de género: un problema de conflicto social. La situación en España Conflicto Social, Año 3, N 4, Diciembre 2010

https://www.researchgate.net/publication/228970044_Violencia_de_genero_un_problema_de_conflicto social La situacion en Espana

Presidencia del Consejo de Ministros. (2011). Cuéntalo todo, cuéntalo bien: Manual para la cobertura de conflictos sociales. Lima.

Programa de la Naciones Unidas para el Desarrollo. (2018). Efectos de la comunicación en la igualdad [Presentación Power Point].

Redacción multimedia. (2017). Ni Una Menos: hombre arrastró por la calle y amenazó de muerte a su pareja en Miraflores (VIDEO). 12 de mayo de 2019, de Correo Sitio web: https://diariocorreo.pe/peru/facebook-video-muestra-sujeto-arrastrar-por-la-calle-su-pareja-en-miraflores$778615 /$

Redacción Multimedia. (2015). Ministerio de la Mujer asuma defensa de mujer agredida en Ayacucho. 12 de mayo del 2019, de Correo Sitio web: https://diariocorreo.pe/peru/ministerio-de-la-mujer-asumadefensa-de-mujer-agredida-en-ayacucho-602846/ 
Redacción multimedia. (2017). Sujeto arrastra por las calles a su pareja y todo queda iregistrado en video!. 12 de mayo del 2019, de Ojo Sitio web: https://ojo.pe/ciudad/sujeto-arrastra-calles-pareja-y-todoqueda-registrado-video-247562/

Redacción Perú 21. (2017). ¡Justicia para Micaela! Arrastró a su pareja por toda la calle bajo amenazas [VIDEO]. 12 de mayo del 2019, de Perú 21 Sitio web: https://peru21.pe/cheka/redes-sociales/sujetoarrastro-pareja-calle-miraflores-379279

Redacción Perú 21. (2018). Ayacucho: Sujeto desnudo arrastró a su ex pareja en un hostal y fue detenido, pero.... 12 de mayo del 2019, de Perú 21 Sitio web: https://peru21.pe/lima/ayacucho-sujeto-desnudoarrastro-ex-pareja-hostal-detenido-188276

Redacción Trome. (2017). Ni una menos: mujer fue arrastrada por la calle por un sujeto en Miraflores [VIDEO]. 12 de mayo del 2019, de Trome Sitio web: https://trome.pe/actualidad/maltrato-mujermiraflores-camino-forsyth-video-64215

Vara-Horna, A. (2019). Los costos económicos de la inacción en la prevención de la violencia contra las mujeres basada en el género en el distrito de Villa El Salvador: 2018. Lima. Programa de Naciones Unidas para el Desarrollo - PNUD.

Velásquez, A.. (2018). Sujeto sube a bus y rocía combustible a pasajera en Miraflores. 12 de mayo del 2019, de La República Sitio web: https://larepublica.pe/sociedad/1232511-sujeto-sube-a-bus-y-rociacombustible-a-pasajera-en-miraflores/1?ref=notagaleria

Zarzalejos, J. (2017). Comunicación, periodismo y "fact checking". Revista UNO, (27), 11-13. Desde: https://www.revista-uno.com/wp-content/uploads/2017/03/UNO_27.pdf

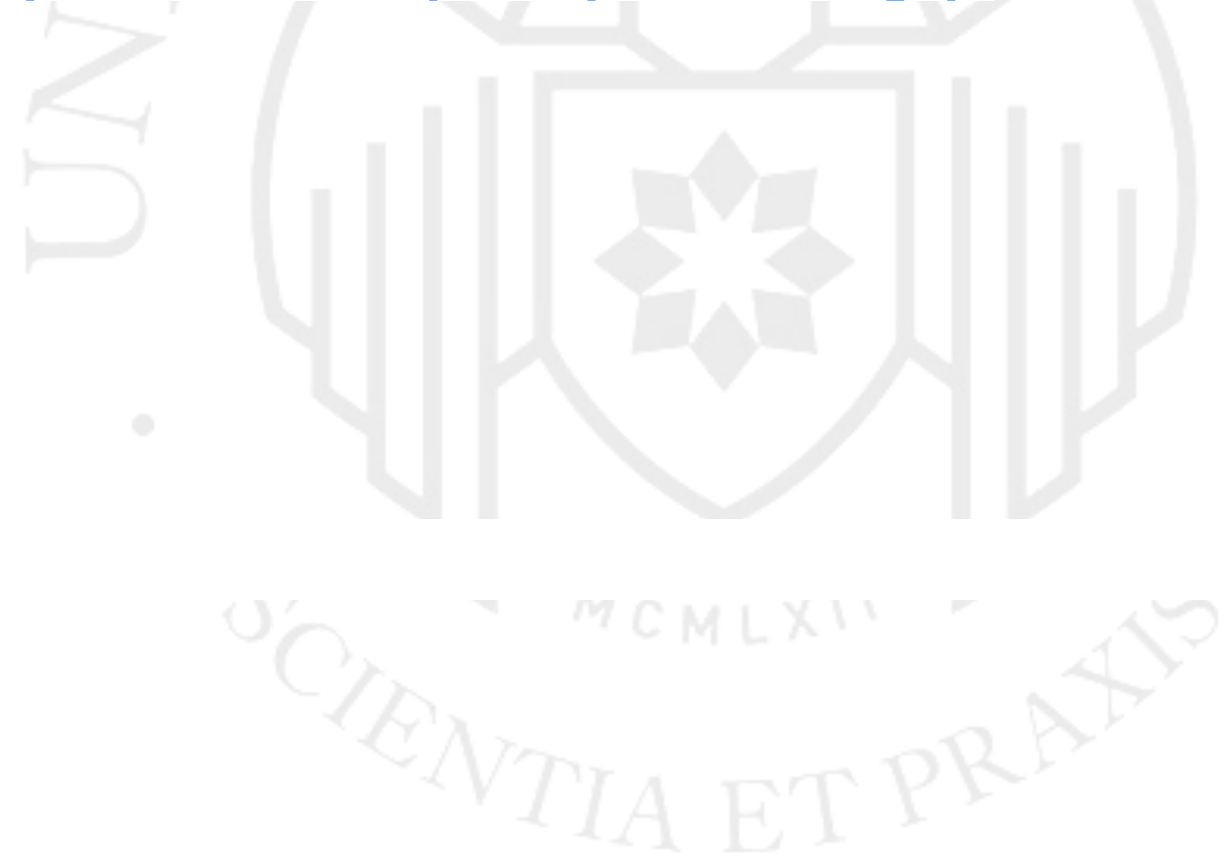




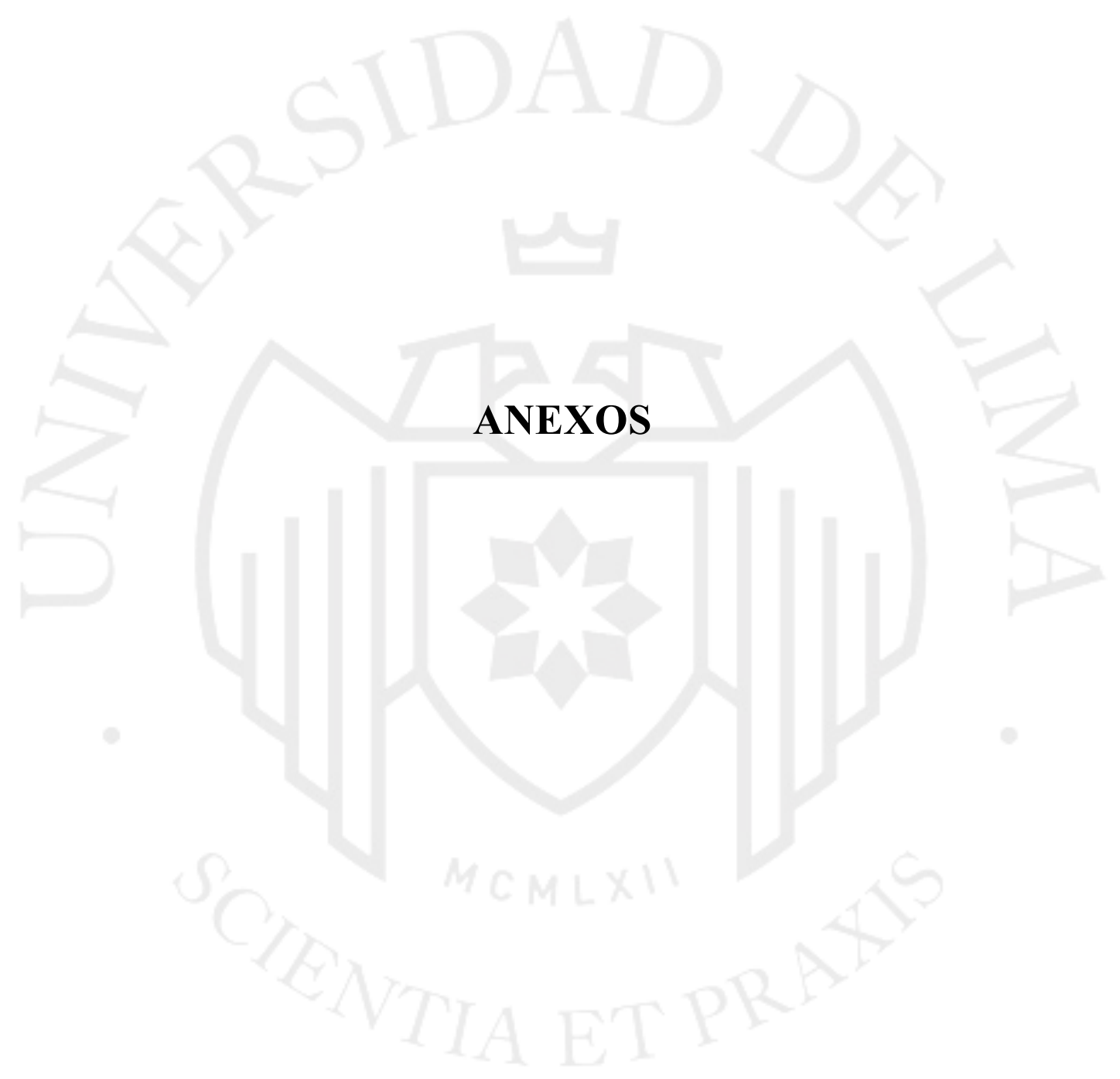




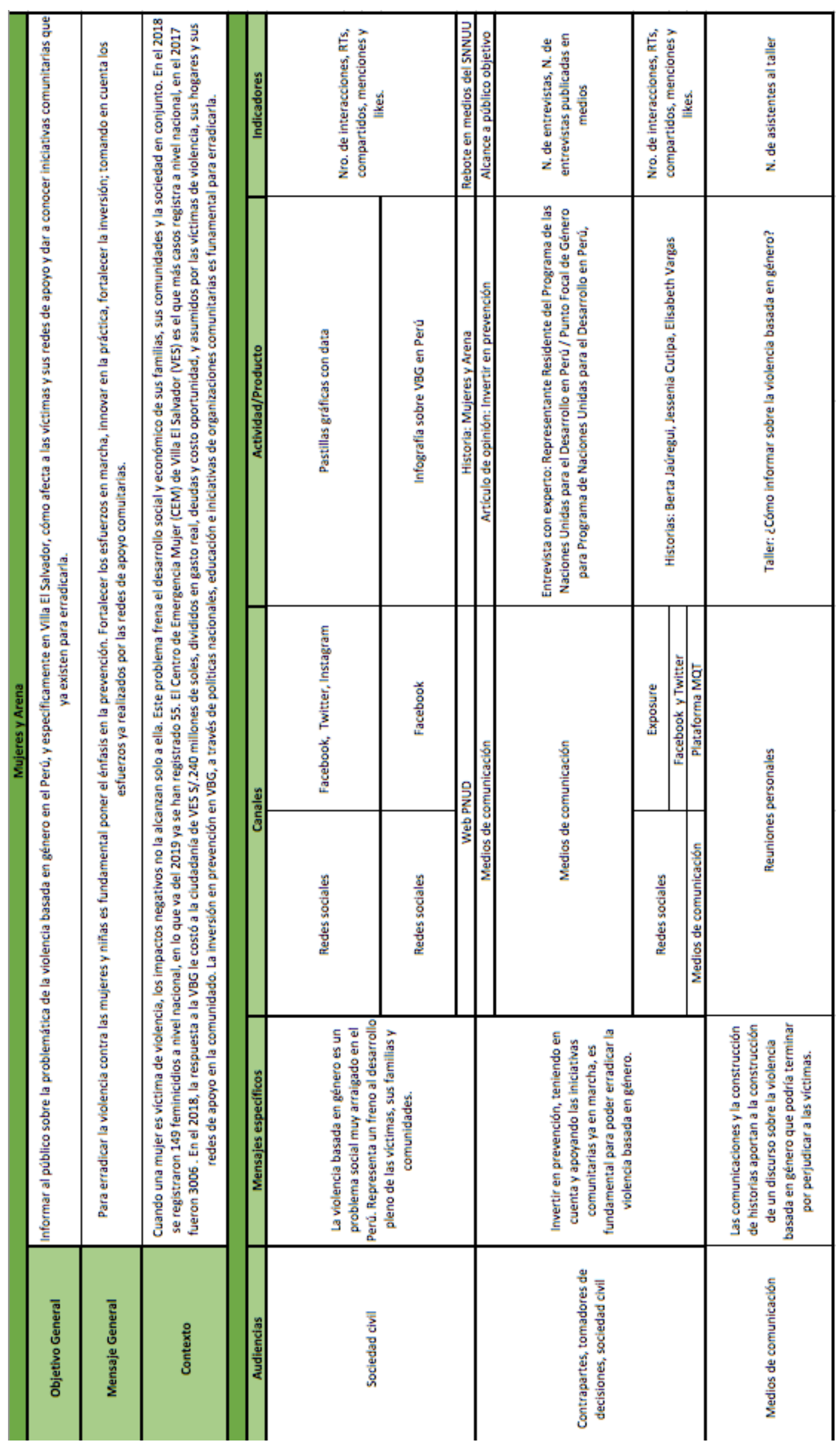




\section{ENLACE A LA PROPUESTA:}

https://drive.google.com/drive/folders/16CwO51KWJnmTe39Sq5dYodUDIT2bjNEo?us

\section{$\mathrm{p}=$ sharing}

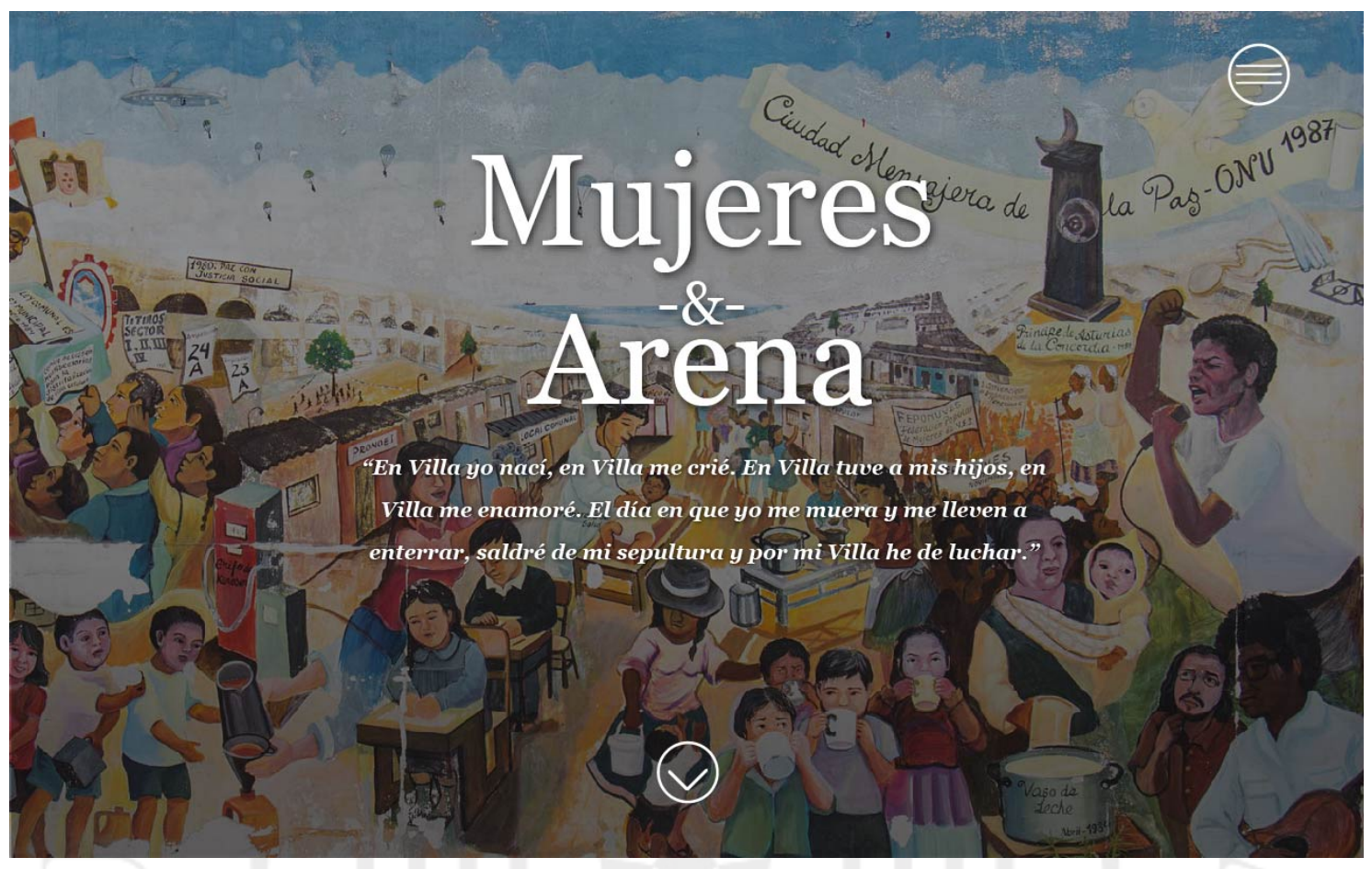

Villa El Salvador es un distrito con mito. Con tradición. Con esperanza y con historia.

Con mujeres valiosas y figuras que se han convertido en ídolos nacionales, en la cara de las organizaciones de base. Mujeres que trabajan todos los días por ayudar a sus compañeras, trabajar con ellas, empoderarlas y cumplir con la esperanza de conocer una sociedad donde ellas se reconozcan a sí mismas como ciudadanas, con el derecho a vivir una vida sin miedo, una vida sin violencia 


\section{CAPÍTULO 1 \\ Villa El Salvador}

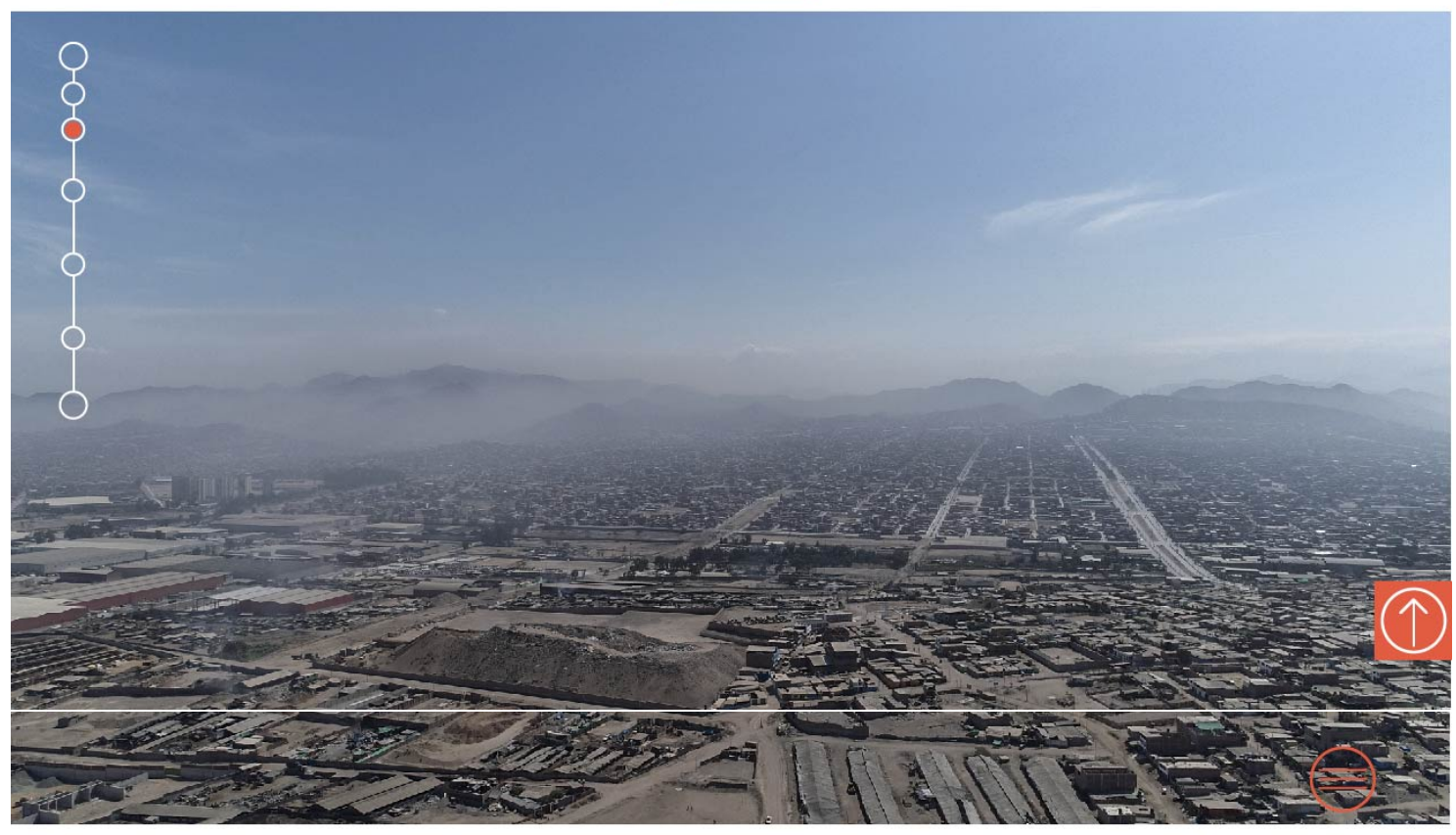

\section{Villa El Salvador nació de la arena.}

En el 71, cientos de familias del interior del país llegaron a Lima buscando nuevas oportunidades, un espacio dónde vivir y construir su historia. Así, del arenal surgió la ciudad. Ahora, el quinto distrito más poblado de Lima lleva sobre sus hombros una historia de organización comunitaria y perseverancia.

En una ciudad que ya es peligrosa para las mujeres, Villa El Salvador es uno de los distritos con más casos de violencia y feminicidio en la capital. En el 2017 se registraron 3006 casos en el Centro de Emergencia Mujer (CEM). Paralelamente, una larga y resonada tradición de organizaciones de mujeres líderes está incrustada en sus cimientos. Una tradición que se mantiene, que ha crecido y evolucionado, y que hoy reúne a los colectivos originales y nuevos en un esfuerzo conjunto, con la esperanza de construir una sociedad y una vida más justa para todas y todos 


\section{La Violencia}

\section{EN EL PERÚ}

\section{Una de cada 3 mujeres ha} sido víctima de violencia fisica o sexual en su vida.

$\mathrm{Y}$ cada 3 minutos se registra una denuncia en algún Centro de Emergencia Mujer a nivel nacional.

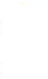

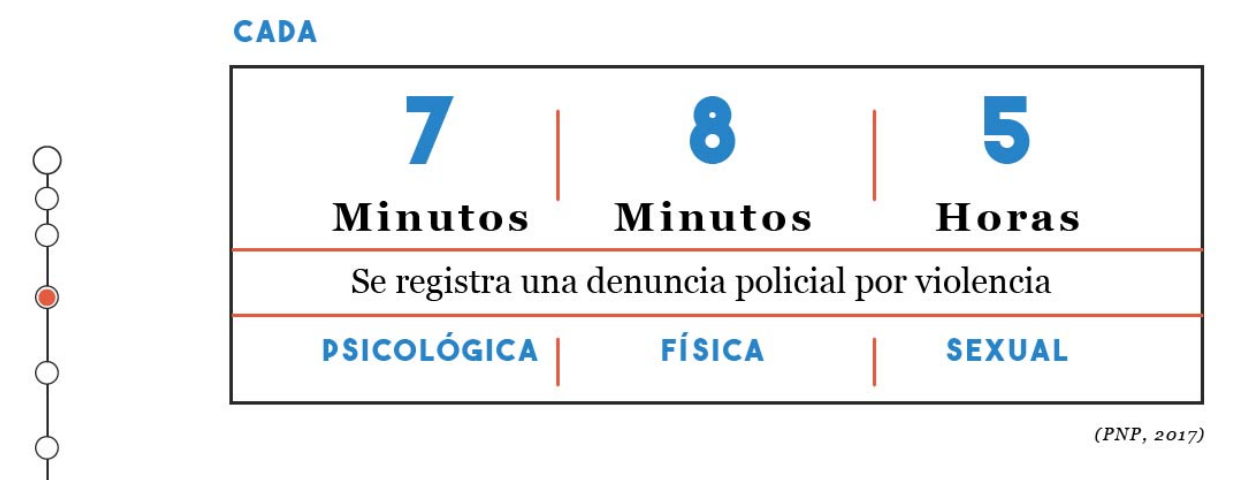

En los últimos años se ha visto un incremento de denuncias policiales y en Centros de Emergencia Mujer, en distintos ámbitos de violencia. Sin embargo, no podríamos asegurar que la violencia ha aumentado, o si ha aumentado la disposición de las mujeres a denunciar. 


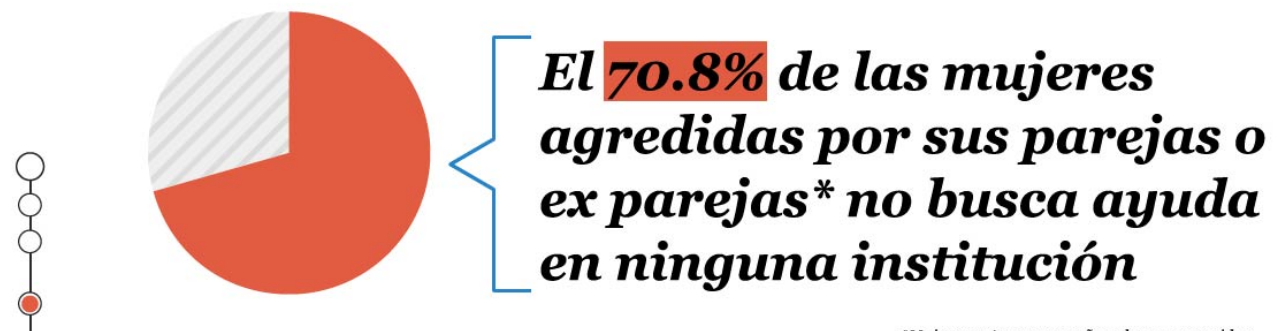

De la misma manera, ha ido incrementando el número de feminicidios año a año. Se calcula un promedio de 10 víctimas al mes.

\section{5 víctimas en 2017}

\section{9 víctimas en 2018}

55 víctimas en 2019 al 3 de mayo

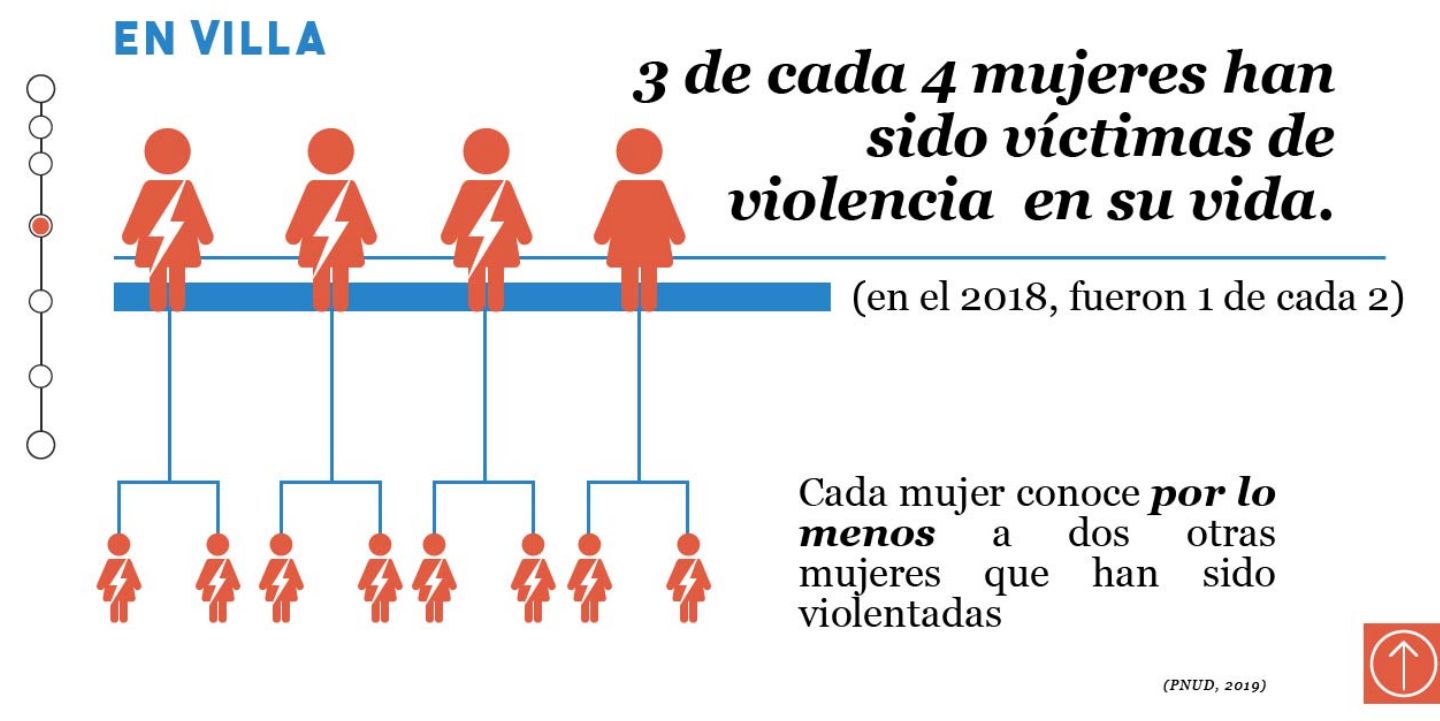




\section{El Costo}

El tejido social de Villa El Salvador (VES) es uno de sus activos más importantes.

Empezando con la construcción del distrito desde los cimientos, la comunidad de VES se ha apoyado entre sí para salir adelante y desarrollarse. La respuesta a la violencia basada en género (VBG) no es ninguna excepción.

\section{La respuesta a la VBG en 2018 costó a la comunidad S/.240 millones}

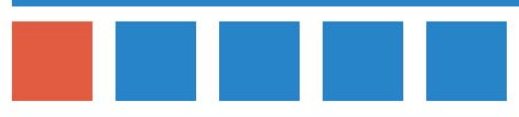

4 veces más que el gasto de la Municipalidad en obras públicas en 2016

Estos costos se reflejan en lo que gasta una víctima en tratamiento médico, en una denuncia en la comisaría, en los transportes para llegar al Centro de Emergencia Mujer; lo que deja de producir cuando pierde días de trabajo por la violencia, lo que dejan de producir las personas que la acompañan, días de clase perdidos por los hijos, entre otros.

\section{La ciudadanía (entre los \\ hogares de las víctimas y su red de apoyo) asumió el 55.3\% de los gastos.}

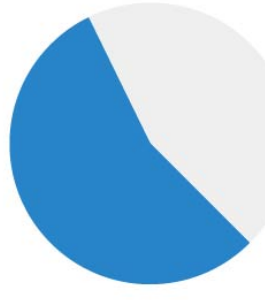


Equivalente a aproximadamente,

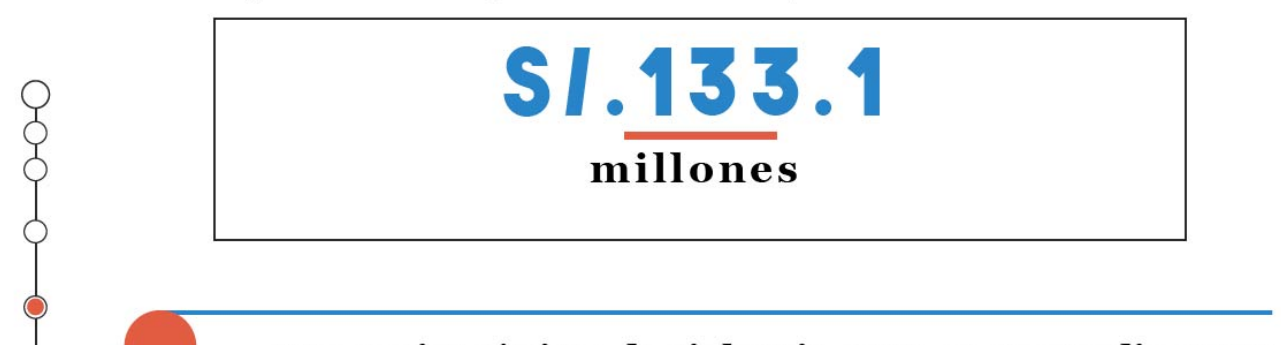

Una mujer víctima de violencia gasta en promedio entre $\mathbf{S} / .1100$ y $\mathbf{S} / .1700$ en respuesta a la violencia, independientemente de si recibe ingresos o no.

En total, las víctimas asumieron el 44.7\% del costo total del 2018 (S/.107.6 millones)

CAPÍTULO 4

\section{Las Mujeres}

En medio del Cementerio Municipal de Villa el Salvador, arriba, al lado del Asentamiento Humano Lomo de Corvina, hay una cruz blanca. Rodeada de arena y pabellones esparcidos casi al azar por el espacio, la cruz se eleva sobre el recuerdo que guardan los nichos. Bajan de la cruz rezando un Ave María, juntos en procesión con flores en la mano. El sol refleja en el arenal y a su vez en los rostros de los vecinos que caminan lento, con pesar en el paso. Maria Elena los espera en silencio, como desde hace 27 años.

\section{Villa cuando niño yo recuerdo, eras pobre, triste y sin luz}

las mujeres reunidas alrededor de la tumba de Maria Elena Moyano cantan con sentimiento. Sus compañeras de lucha, del Vaso de Leche, los comedores populares, se reúnen todos los años a rendir sus respetos a una mujer que se convirtió en un ícono en el distrito, en una figura nacional. 
A través del trabajo coordinado, solidario y perseverante, lograron construir una ciudad donde no había nada. Desde donde están, en la cima, con Villa a los pies, es difícil imaginar algún momento cuando la inmensidad de Villa el Salvador no existió. Y las mujeres que siguen paradas en el cementerio, cantando en arengas iViva Villa!, iMaria Elena Moyano presente, hoy y siempre!, son las que siguen luchando y trabajando para combatir los problemas que aún aquejan al distrito.

En la casa refugio de la Federación Popular de Mujeres de Villa el Salvador (FEPOMUVES), el calor es sofocante. El Colectivo de Concertación por la Equidad de Género se reúne alrededor de una mesa de madera que no puede contenerlas a todas. Son en su mayoría mujeres mayores, curtidas por los años, el trabajo dedicado y el sol en el arenal. Mujeres que conocen Villa el Salvador desde que nació, que lo vieron crecer y desarrollarse y saben el potencial que tiene para ser más, mucho más de lo que es ahora.

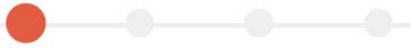

\section{RAÍCES}

\section{Berta Jaúregui}

La historia de Berta es la de esa primera generación de mujeres que ha marcó al distrito. Una mujer que "salió de su casa", una madre de familia joven, que a través de la organización encontró su voz y su vocación de transformación a través de su liderazgo.

Empezó el camino en comedores populares y comités de arborización, esfuerzos por sacar el distrito adelante y asegurar el bienestar de la gente. Berta recuerda que los hombres salían a trabajar y eran ellas quienes se quedaban apropiándose del territorio y transformándolo. En este contexto, las primeras organizaciones de mujeres emprendieron rumbo. 
Necesitaban que se reconociera su trabajo y participación, que se escuchara su voz. A partir de la creación de la primera Federación Popular de Mujeres de Villa El Salvador (FEPOMUVES) en el 83, empezó este reconocimiento y se fortaleció el trabajo. Se crearon los comités de Vaso de Leche, se multiplicaron los comedores, y más allá de la generación de espacios necesarios para la supervivencia, empezó el trabajo por apoyar a las mujeres que sufrían de violencia, "Mujeres como tú, como yo" dice Berta.

A través de su trabajo con la Federación, y ahora con el Colectivo de Concertación por la Equidad de Género, ha podido participar de diversas iniciativas para la eliminación de la violencia contra la mujer, un problema que termina por afectar a todas y todos.

\section{Una mujer violentada se vuelve un problema no solo para la sociedad, sino para el país."}

Las iniciativas de las que Berta participó incluyen el fortalecimiento de instituciones, el mapeo de zonas de riesgo en el distrito y el trabajo por posicionar prioridades fundamentales para las mujeres en las agendas políticas de las autoridades municipales. Asimismo, la capacitación de las mujeres mismas, su empoderamiento para reconocerse como sujetos de derecho, que pueden vivir una vida sin violencia.

Actualmente, sin embargo, existe una importante brecha generacional que hay que trabajar. Las y los jóvenes deben recuperar la tradición de la organización y conocer la historia de su distrito. "Existe un divorcio", dice Berta, "entre las nuevas generaciones y el mito de Villa El Salvador". En la medida en la que lo conozcan y recuperen este mito, podrán trabajar en la prevención de la violencia de género y construir su identidad a través de su historia.

\section{La identidad de un pueblo se adquiere a través de su historia."}




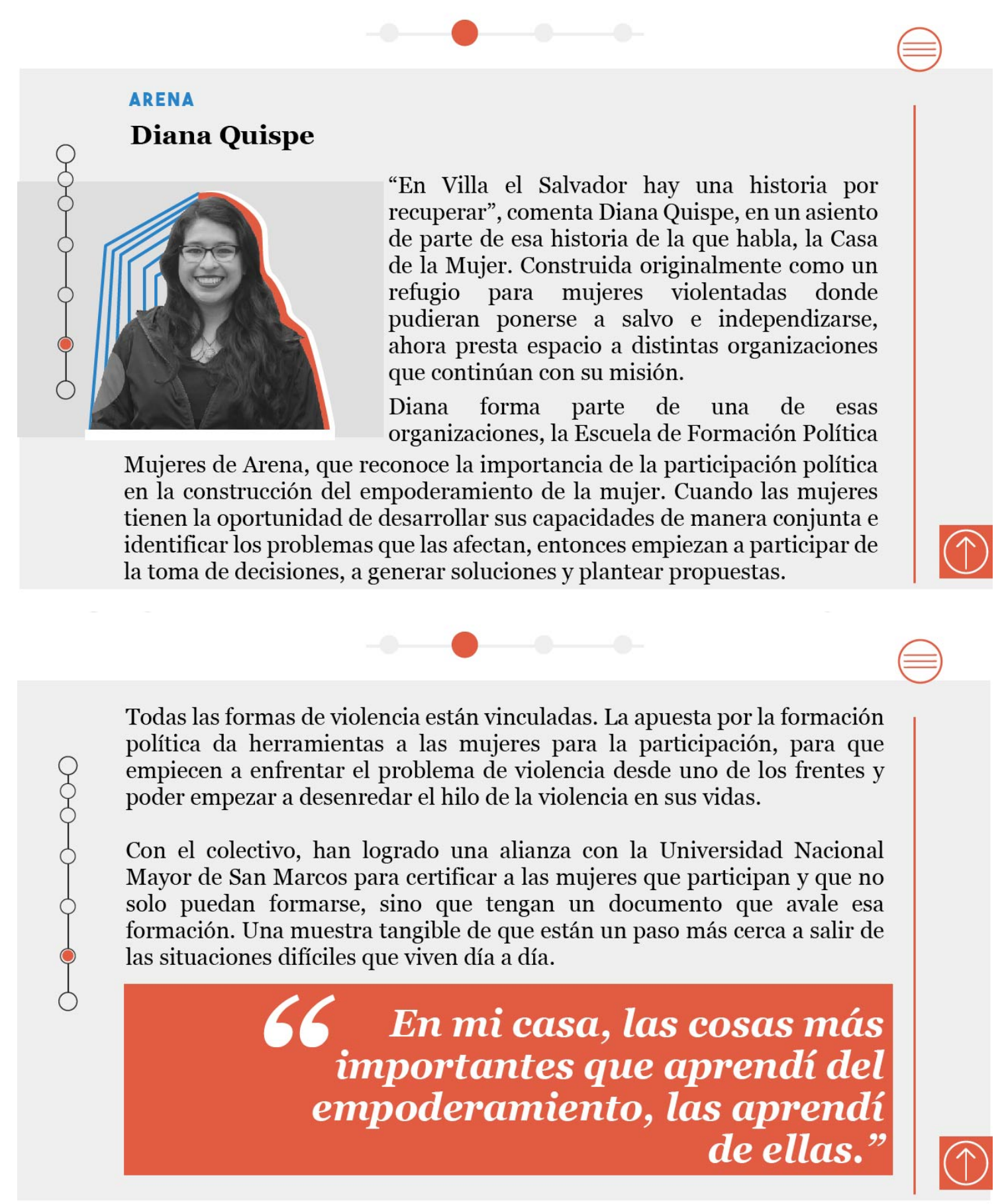



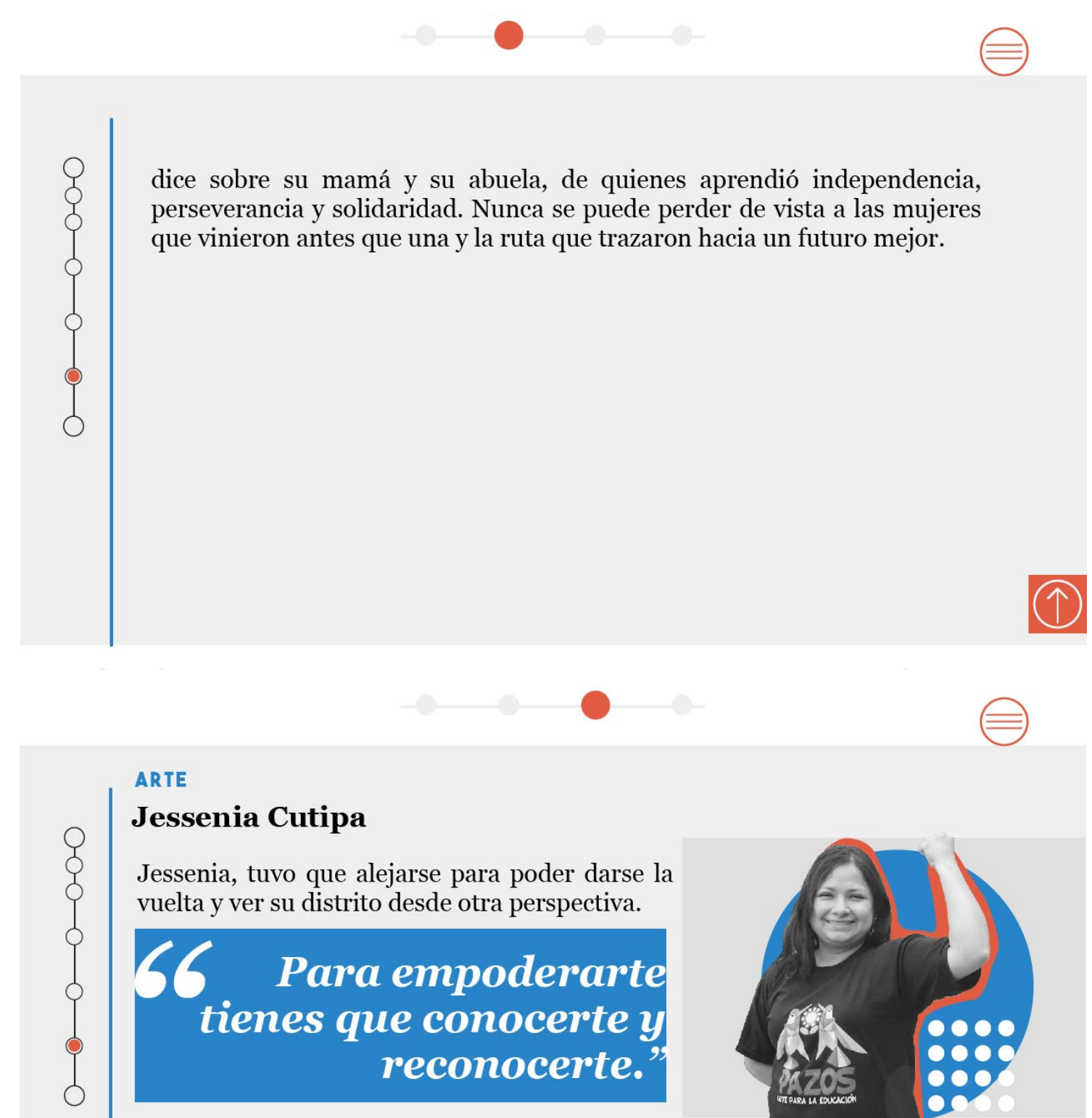

Reconocer que los roles violentos, los estereotipos de género existían en su distrito y los vivía ella misma en su día a día motivó la necesidad de generar un cambio.

La organización Pazos, Arte para la Educación, y más específicamente, la escuela Pazos de Mujer, le han servido como plataformas para poder 
trabajar en contra de esos roles y ayudar a las mujeres que también los reconocen en sus vidas, haciendo uso de las artes como una estrategia de entrada para un tema difícil como la violencia contra la mujer.

A través de talleres de teatro y batucada las mujeres de la escuela aprenden a conocerse, a tener una relación más íntima consigo mismas y con sus compañeras. Se crea un espacio seguro, de confianza. Aprenden también, a identificar cosas de ellas mismas en otras, cosas similares, duras y violentas. En estos espacios de conversación, las mujeres que han sido violentadas se encuentran en comunidad, encuentran cosas que las unen, y se crean redes, conexiones humanas fundamentales para reconocer que no están solas y no tienen que estarlo.

El arte como herramienta de liderazgo y transformación abre las puertas a un tipo de sensibilización particular, dice Jessenia. El arte te mueve, te transforma, y presta un espacio para conocer experiencias duras, reflexionar y generar una propuesta para enfrentar la violencia y manifestar lo que sienten estas mujeres

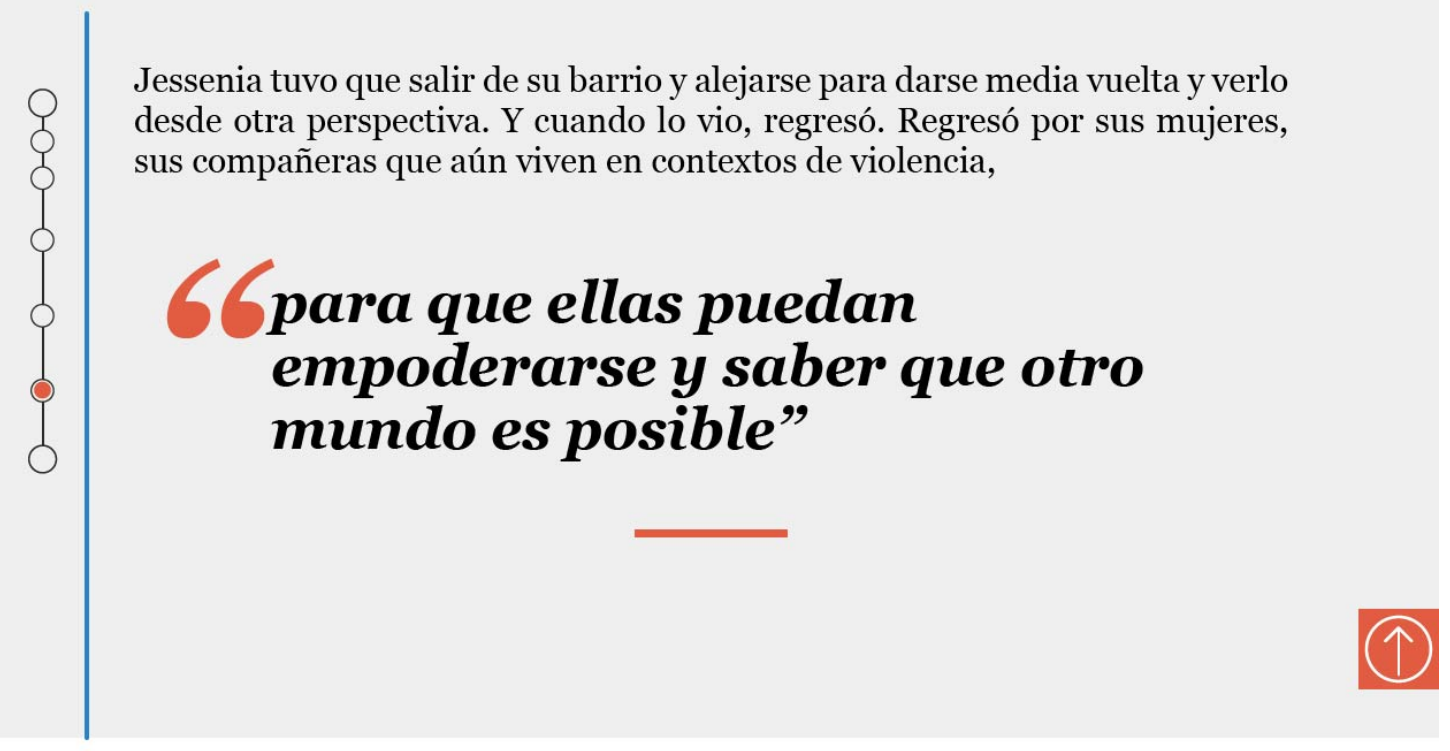




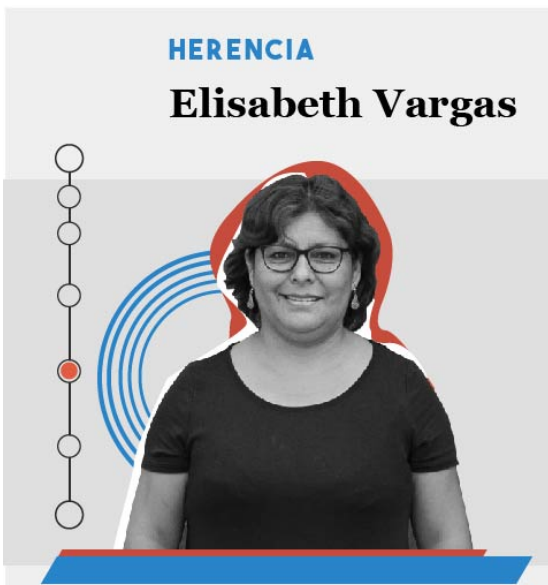

Elisabeth recuerda su infancia en Villa. El arenal limpio de las primeras invasiones, que reflejaba la luz de luna llena en conchitas blancas que parecían estrellas. Recuerda, también, la comunidad, la cooperación y la organización. A sus padres techando casas con los vecinos, las colas para sacar agua y el sentimiento de unión que cada una de las personas que llegaron a Villa el Salvador infundieron en su trabajo para hacer nacer el distrito.

Ahora todo es más individualista, dice. Más cerrado. Hay que recuperar.

Con el pasar de los años, se ha hecho cada vez más difícil involucrar a la juventud villasalvadoreña en el sentimiento de comunidad de los fundadores

del distrito. Por diferentes motivos, la vocación de trabajar por los demás no está tan presente como en el inicio y esto ha creado una importante brecha generacional, que debe cerrarse para poder continuar con el trabajo y el desarrollo, que mantenga vivos a los colectivos a lo largo del tiempo.

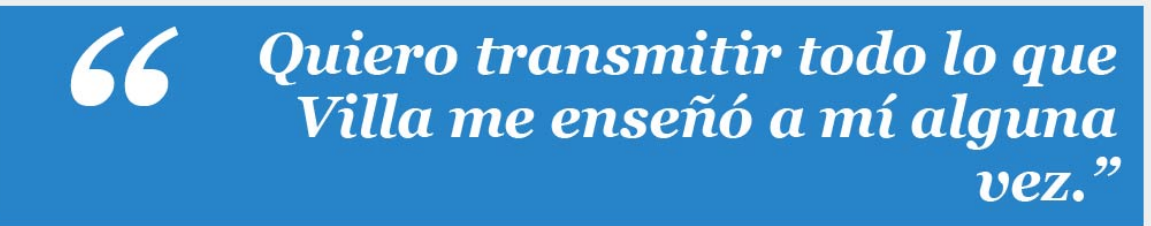

Ella ha encontrado que el activismo le ha permitido tener una relación más estrecha con sus hijas, y espera que ese pudiera ser el caso con todas las familias de Villa. "Todos sueñan con una familia con la que puedan construir desarrollo, no solo para ellos, para todo el distrito."

A través del colectivo Mujeres de Arena, Elisabeth y sus compañeras trabajan para empoderar a quienes llevaron el liderazgo de las organizaciones iniciales, validando con evidencia todo lo que ellas 
aprendieron sobre la marcha de liderazgo, política y la transformación del distrito. Empoderándolas para que puedan ocupar posiciones de toma de decisiones en organismos como la municipalidad, y que todo lo que saben lo puedan transmitir y poner en práctica. Al mismo tiempo, buscan invitar a cualquier mujer que quiera a formarse en política, para que ellas también puedan aprender y transformar.

Elisabeth ha aprendido con los años, y quiere que otras aprendan también. "En algún momento ya no vas a estar, y no te puedes ir con lo que tienes" y ella quiere dejar al resto, todo lo que Villa le dio.

\section{CADÍTULO 5 \\ La Respuesta}

La forma más efectiva de avanzar hacia la eliminación de la violencia basada en género y sus consecuencias, es trabajar en preveción. Así como las mujeres de Villa El Salvador vienen trabajando desde sus diversas iniciativas, el Estado peruano ha trabajado también en tres, importantes, dando un paso más hacia adelante en la lucha contra la VBG.
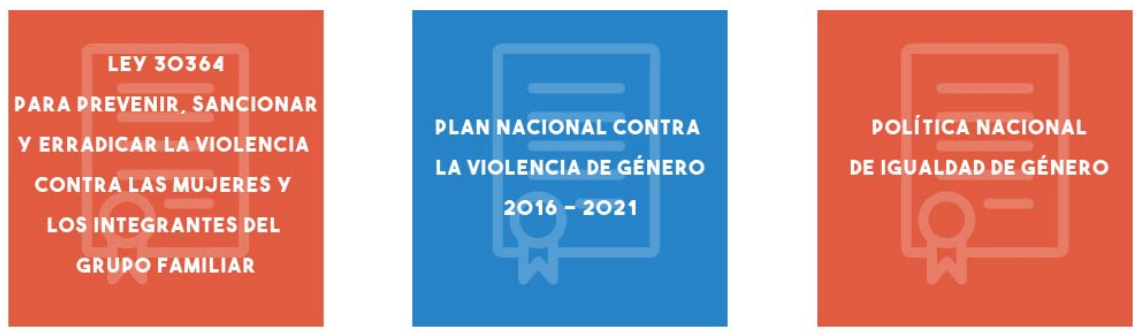


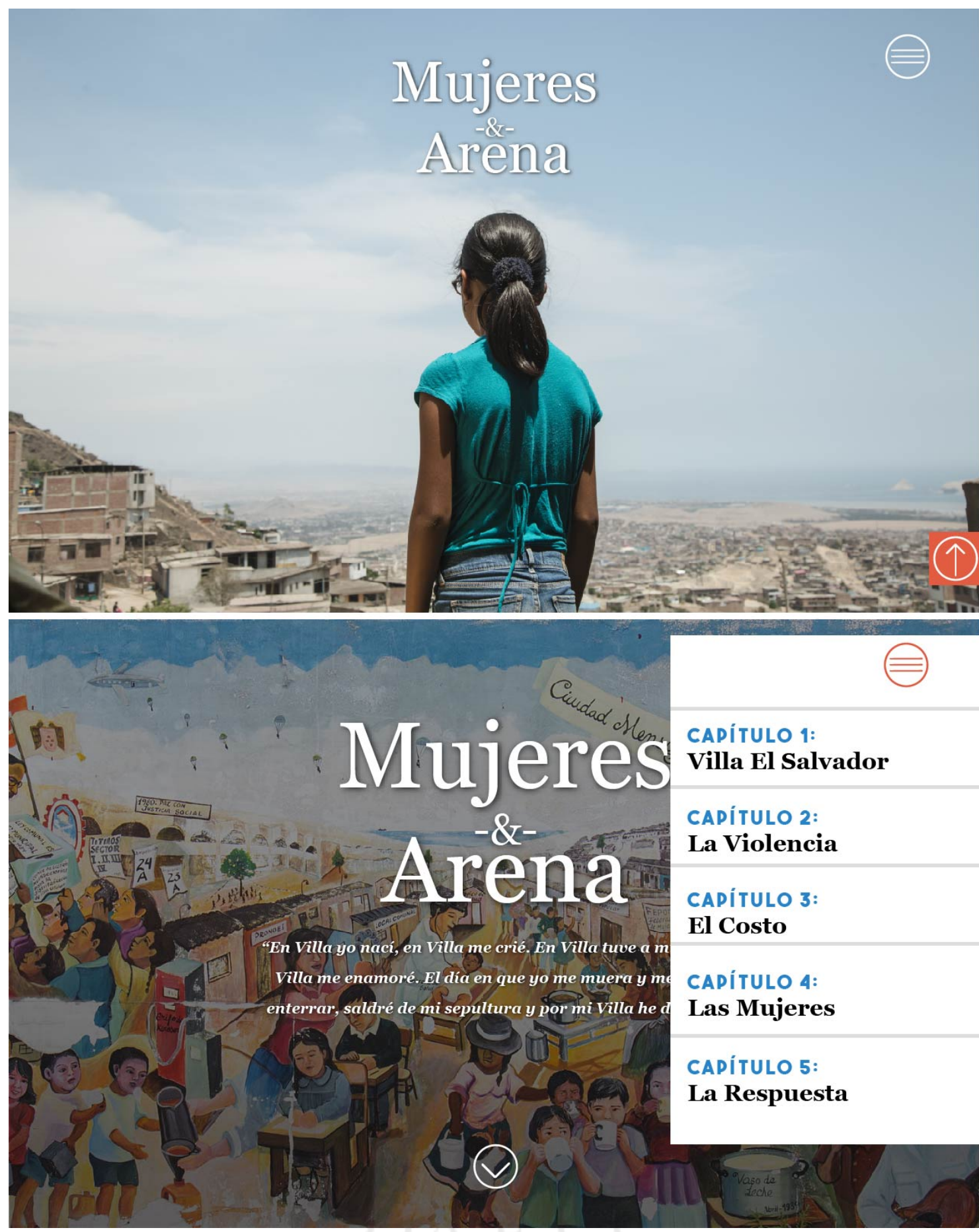

